\title{
Marijuana, Alcohol and Actual Driving Performance
}


This publication is distributed by the U.S. Department of Transportation, National Highway Traffic Safety Administration, in the interest of information exchange. The opinions, findings and conclusions expressed in this publication are those of the author(s) and not necessarily those of the Department of Transportation or the National Highway Traffic Safety Administration. The United States Government assumes no liability for its contents or use thereof., If trade or manufacturer's name or products are mentioned, it is because they are considered essential to the object of the publication and should not be construed as an endorsement. The United States Government does not endorse products or manufacturers. 
Technical Report Documentation Page

\begin{tabular}{|c|c|c|}
\hline $\begin{array}{l}\text { 1. Report No. } \\
\text { DOT HS } 808939\end{array}$ & 2. Government Accession No. & 3. Recipient's Catalog No. \\
\hline \multirow{2}{*}{\multicolumn{2}{|c|}{$\begin{array}{l}\text { 4. Title and Subtitle } \\
\text { Marijuana, Alcohol and Actual Driving Performance }\end{array}$}} & 5. Report Date \\
\hline & & $\begin{array}{l}\text { 6. Performing Organization Code } \\
\text { IHP } \\
\end{array}$ \\
\hline \multicolumn{2}{|c|}{$\begin{array}{l}\text { 7. Author(s) } \\
\text { Hindrik W. J. Robbe, Ph.D. and Jam }\end{array}$} & $\begin{array}{l}\text { 8. Performing Organization Report No. } \\
\qquad \text { P44-E1 }\end{array}$ \\
\hline \multirow{3}{*}{\multicolumn{2}{|c|}{$\begin{array}{l}\text { 9. Performing Organization Name and Address } \\
\text { Institute for Human Psychopharmacology } \\
\text { Maastricht University } \\
\text { P. O. Box } 616 \\
6200 \text { MD Maastricht, The Netherlands }\end{array}$}} & 10. Work Unit No. (TRAIS) \\
\hline & & 11. Contract or Grant No. \\
\hline & & \multirow[t]{2}{*}{ 13. Type of Report and Period Covered } \\
\hline \multirow{2}{*}{\multicolumn{2}{|c|}{ 12. Sponsoring Agency Name and Address }} & \\
\hline & & 14. Sponsoring Agency Code \\
\hline
\end{tabular}

15. Supplementary Notes

16. Abstract

The purpose of this study was to empirically determine the separate and combined effects of Delta-9-tetrahydrocannabinol (THC) and alcohol on actual driving performance. This was the first study ever in which the drugs' combined effects were measured in a natural setting, i.e., on real roads in normal traffic.

Eighteen subjects between 20 and 28 years of age who were licensed to drive an automobile and who smoked marijuana and drank alcohol at least once per month participated in the study. They were treated with drugs and placebo according to a balanced, 6-way, observer- and subject-blind, cross-over design. On separate evenings they were given weight-calibrated doses of THC and alcohol, or placebos for one or both substances as follows: alcohol placebo + THC placebo; alcohol placebo + THC $100 \mathrm{~g} / \mathrm{kg}$; alcohol placebo + THC $200 \mathrm{~g} / \mathrm{kg} ;$ alcohol + THC placebo; alcohol + THC $100: \mathrm{g} / \mathrm{kg} ;$ and, alcohol + THC 200 $: \mathrm{g} / \mathrm{kg}$. The initial alcohol dose was sufficient for achieving a peak blood alcohol concentration (BAC) of about $0.07 \mathrm{~g} / \mathrm{dl}$. Booster doses were later given to sustain BAC around $0.04 \mathrm{~g} / \mathrm{dl}$ during testing.

At each occasion, $30 \mathrm{~min}$. after smoking, subjects performed four driving tests in the evening hours after dark between 21:00 and 23:15: two repetitions of a Road Tracking Test and two repetitions of a Car Following Test. The former test measured the subjects' ability to maintain a constant speed of $100 \mathrm{~km} / \mathrm{h}(62 \mathrm{mph})$ and a steady lateral position between the delineated boundaries of the right (slower) traffic lane. The latter test measured the subjects' reaction times and headway variability while driving $50 \mathrm{~m}$ (164 ft) behind a preceding vehicle that executed a series of alternating acceleration and deceleration maneuvers. Both THC doses alone, and alcohol alone, significantly impaired the subjects' Road Tracking and Car Following performances. The magnitude of the mean effects were minor after alcohol and THC $100: \mathrm{g} / \mathrm{kg}$ and moderate after THC $200: \mathrm{g} / \mathrm{kg}$. Both THC doses in combination with alcohol severely impaired the subjects' performance in both tests. While the effects of THC alone in doses up to $200: \mathrm{g} / \mathrm{kg}$ might be categorized as "moderate", they become "severe" when THC is combined with a moderate dose of alcohol.

\begin{tabular}{|l|l|l|l|}
\hline $\begin{array}{l}\text { 17. Key Words } \\
\text { Alcohol, marijuana, driving performance, ethanol, THC, } \\
\text { highway safety, traffic safety, drugs and driving }\end{array}$ & $\begin{array}{l}\text { 18. Distribution Statement } \\
\text { Document available to the public through the } \\
\text { National Technical Information Service, } \\
\text { Springfield, VA 22161 }\end{array}$ \\
\hline \begin{tabular}{l|l|l|l|} 
19. Security Classif. (of this report) & 20. Security Classif. (of this page) & 21. No. of Pages & 22. Price \\
\hline
\end{tabular} & \multicolumn{1}{|c|}{ Unclassified } & 43 \\
\hline
\end{tabular}

Form DOT F 1700.7 (8-72) Reproduction of completed page authorized

This form was electronically produced by Elite Federal Forms, Inc. 


\section{CONTENTS}

ACKNOWLEDGMENTS

2. METHODS

2.1 Subjects

2.2 Legality and Ethics 14

2.3 Design, Doses and Administration $\quad 14$

2.4 Procedures $\quad 15$

2.5 Driving Tests and Rating Scales 16

$\begin{array}{ll}2.6 \text { Statistical Analysis } & 19\end{array}$

3. RESULTS 21

3.1 Adjustments for Missing Data $\quad 21$

3.2 Blood Alcohol Concentration (BAC) 22

3.3 Road Tracking $\quad 23$

3.4 Car Following $\quad 27$

3.5 Intoxication Ratings $\quad 29$

3.6 Driving Quality Ratings 29

3.7 Instructor's Comments $\quad 32$

$\begin{array}{ll}\text { 4. DISCUSSION } & 34\end{array}$

5. CONCLUSIONS $\quad 39$

$\begin{array}{ll}5.1 \text { General Conclusions } & 39\end{array}$

$\begin{array}{ll}5.2 \text { Specific Conclusions } & 40\end{array}$

6. REFERENCES 41 


\section{ACKNOWLEDGMENTS}

This report is the second that emerged from programmatic marijuana research conducted by the Institute for Human Psychopharmacology, Maastricht University, under contract to the National Highway Traffic Safety Administration (NHTSA) of the US Department of Transportation. We thank NHTSA for supporting the research program and Mr. Ted Anderson and Dr. James Frank for monitoring it. We appreciate the cooperation of the US National Institute on Drug Abuse (NIDA) for providing the marijuana cigarettes.

The contract has been locally administered by the Dutch Road Safety Directorate of the Ministry of Transport and Public Works under an intergovernmental agreement, and we would like to thank Dr. Jan Busstra for monitoring the project locally.

We are grateful to the District Attorney, Mr. H.W. Overbosch, and the Maastricht University's Institutional Review Board for reviewing and approving the study. A permit for obtaining, storing and administering marijuana was obtained from the Dutch Drug Enforcement Administration.

We'd like to thank our colleagues, Cees van Leeuwen, MD, and Nienke Muntjewerff, MD, for the medical supervision; Anita van Oers and Aldrik Schmitz du Moulin for their assistance during data collection; and, Henk Brauers and Pitou Sweens, our licensed driving instructors, for their important contribution of supervising the subjects while driving. Finally we thank the subjects for their participation. 
Marijuana / Alcohol Driving Study

\section{EXECUTIVE SUMMARY}

Previous driving simulator and closed-course studies have failed to confirm what epidemiologists' data suggest, i.e., that alcohol and $\Delta^{9}$-tetrahydrocannabinol (THC) interact synergistically to produce greater impairment than the sum of the changes that each drug produces separately. Yet with the methodological shortcomings of particular studies and the general lack of test realism afflicting all, it can not be said that their failure to measure a synergistic effect is particularly convincing.

The study described in this report represents another attempt to empirically determine the separate and combined effects of THC and alcohol on driving. It differs from its predecessors by employing standardized tests for objectively measuring the drugs' effects on driving performance in the natural environment; i.e., on real roads in normal traffic.

Eighteen volunteer subjects, comprised of men and women in equal proportions, participated in the present study. The subjects were all university students between 20 and 28 years of age who smoked marijuana and drank alcohol at least once per month. All admitted having previously driven under the influence of each drug separately but only three, of both together. They were treated with drugs and placebo according to a balanced, 6-way, observer- and subject-blind, cross-over design. On separate evenings they were given weight-calibrated doses of THC and alcohol, or placebos for one or both substances as follows: alcohol placebo + THC placebo; alcohol placebo + THC $100 \mu \mathrm{g} / \mathrm{kg}$; alcohol placebo + THC $200 \mu \mathrm{g} / \mathrm{kg}$; alcohol + THC placebo; alcohol + THC $100 \mu \mathrm{g} / \mathrm{kg}$; and, alcohol + THC $200 \mu \mathrm{g} / \mathrm{kg}$. The initial alcohol dose was sufficient for achieving a peak blood alcohol concentration (BAC) of about $0.07 \mathrm{~g} / \mathrm{dl}$. Booster doses were later given to sustain BAC around $0.04 \mathrm{~g} / \mathrm{dl}$ during testing. THC was administered by smoking marijuana cigarettes $(2.2$ and $3.95 \%$ THC from the US National Institute on Drug Abuse, NIDA) which had been weight-calibrated by cutting. Initial drinking preceded smoking by $60 \mathrm{~min}$.

Driving tests began $30 \mathrm{~min}$. after smoking at $21: 00 \mathrm{hr}$. Subjects undertook them in pairs on the same evening. One started with the Car Following Test and the other 4 min. later with the Road Tracking Test. After driving on the highway for approximately $25 \mathrm{~min}$., the first subject drove off and awaited the second. When he/she arrived, the pair exchanged roles, returned to the highway, and drove in the reverse direction until returning to the origin. The same procedure was repeated twice so that each subject completed two repetitions of each test. Testing concluded at approximately $23: 15 \mathrm{hr}$.

Subjects were accompanied by licensed driving instructors having access to redundant vehicle controls. In the Road Tracking Test, the subject attempted to maintain a constant speed of $100 \mathrm{~km} / \mathrm{h}(62 \mathrm{mph})$ and a steady lateral position between the delineated boundaries 


\section{Marijuana / Alcohol Driving Study}

of the right (slower) traffic lane. Standard deviation of lateral position (SDLP) was the primary outcome variable. SDLP is a measure of road tracking error, in practical terms, a composite index of allowed weaving, swerving and overcorrecting. Failures to restrict the vehicle's lateral motion within lane boundaries were recorded together as the percentage of time out of lane (TOL). The Car Following Test involved the use of two vehicles. The preceding vehicle was under an investigator's control, and the following vehicle, the subject's. The test began with the two vehicles traveling in tandem at speeds of $100 \mathrm{~km} / \mathrm{h}$ ( $62 \mathrm{mph})$. Subjects attempted to drive $50 \mathrm{~m}(164 \mathrm{ft})$ behind the preceding vehicle and to maintain that headway as it executed a series of alternating acceleration and deceleration maneuvers lasting $33 \mathrm{sec}$ apiece. The investigator driving the preceding vehicle initiated each maneuver by activating a microprocessor-driven cruise-control. The vehicle's speed then rose or fell in a constant manner until arriving at a point $15 \mathrm{~km} / \mathrm{h}(9.3 \mathrm{mph})$ higher or lower than where it began. The investigator drove at the newly established speed for 0.5-5.0 min. before initiating the next maneuver. About eight maneuvers in each direction were accomplished over both repetitions of the test. Headway was continuously recorded as were the subject's discrete reaction times (RTs) at the beginning of maneuvers. Average RT and the standard deviation of headway $\left(\mathrm{H}_{\mathrm{SD}}\right)$ for acceleration and deceleration maneuvers, separately, were the major dependent variables. Subjects rated their degrees of intoxication before and after the entire series of tests. They also rated the quality of their driving performance at the end of each test repetition. The instructors likewise rated the subject's driving quality at the same times and in the same manner.

In statistical terms, both THC doses alone, and alcohol alone, significantly impaired the subjects' Road Tracking and Car Following performances. In practical terms, the magnitude of the mean effects were minor after alcohol and THC $100 \mu \mathrm{g} / \mathrm{kg}$ and moderate after THC $200 \mu \mathrm{g} / \mathrm{kg}$. Both THC doses in combination with alcohol severely impaired the subjects performance in both tests. The mean changes in SDLP from the placebo level after combinations involving THC 100 and $200 \mu \mathrm{g} / \mathrm{kg}$ were evaluated relative to a previously established alcohol calibration curve (Louwerens et al, 1987). The former combination produced a rise in mean SDLP the equivalent of that associated with $\mathrm{BAC}=0.09 \mathrm{~g} / \mathrm{dl}$, and the latter, the equivalent of $\mathrm{BAC}=0.14 \mathrm{~g} / \mathrm{dl}$. Mean TOL rose exponentially with SDLP. Beginning at the placebo level of $0.2 \%$, mean TOL increased with the severity of drug effects until reaching $1.1 \%$ after the combination of alcohol and THC $200 \mu \mathrm{g} / \mathrm{kg}$. Mean RT and $\mathrm{H}_{\mathrm{SD}}$ during deceleration maneuvers varied across treatment conditions in the same manner. Beginning at the placebo level of $4.65 \mathrm{sec}$, mean RT lengthened to $6.33 \mathrm{sec}(+36 \%)$ under the combined influence of alcohol and THC $200 \mu \mathrm{g} / \mathrm{kg}$. The change in mean $\mathrm{H}_{\mathrm{SD}}$ was from 5.69 to $7.78 \mathrm{~m}(+37 \%)$. The subjects' and instructors' rating of driving quality clearly reflected the adverse objective effects of alcohol and THC alone and in combination. In addition, the instructors spontaneously recorded several cases, usually in combined drug 
conditions, wherein a subject's aberrant behavior would have been dangerous were he/she to operate the same way under natural driving conditions.

We concluded that marijuana smoking that delivers the relatively low-moderate THC doses of 100 and $200 \mu \mathrm{g} / \mathrm{kg}$ impairs Road Tracking and Car Following performance. THC effects are dose-related and persist unabated or even increase during $2 \frac{1}{2} \mathrm{hr}$ after dosing. The magnitudes of impairment observed after these doses of THC alone were not especially large in historical comparison to those of other drugs and alcohol present in BACs above $0.08 \mathrm{~g} / \mathrm{dl}$. However, they do imply a loss of driving ability that could be serious in exceptional traffic situations. The combination of THC with alcohol sufficient for attaining a $\mathrm{BAC}$ of about $0.04 \mathrm{~g} / \mathrm{dl}$ has very severe effects on driving performance. Subjects showing those effects drove in a manner one would expect for drivers operating with BACs above the per se definition of intoxication in some states, i.e., $0.08 \mathrm{~g} / \mathrm{dl}$. No unequivocal evidence emerged from this study to indicate that the drug interaction is synergistic in the classic pharmacological sense. However, the exponential rise of TOL from conditions where THC and alcohol were given separately to those where they acted in combination suggests that the interaction can increase the risk of certain types of crashes in the same manner. That being the case, the practical consequences of driving after the combined use of THC and alcohol would be the same whether their pharmacological interaction is synergistic or merely additive. 
Marijuana / Alcohol Driving Study

\section{INTRODUCTION}

There is no doubt that $\Delta^{9}$-tetrahydrocannabinol (THC) impairs its users' cognitive and psychomotor abilities to an extent largely determined by the inhaled or ingested dose. It is also certain that the dose preferred by cannabis smokers (around $300 \mu \mathrm{g} / \mathrm{kg}$ ) is sufficient for impairing performance in potentially dangerous tasks such as driving (Robbe \& O'Hanlon, 1993). It is less certain that those doses cause the degrees of impairment that seriously compromise driving ability, and if they do, whether many THC users choose to drive in that condition. Both the severity of the users' impairment and their prevalence among the driving population could be determined from an epidemiological survey measuring the relative frequencies among drivers who do and do not become involved in crashes. These data would permit calculation of the THC users' risk of crashing relative to that of drug-free drivers. Relative risk (RR) is in fact the only commonly accepted index of any drug's hazard potential for individual drivers, and in direct proportion to its usage prevalence, for the driving population as a whole. Yet more than 20 years of epidemiological research on THC has failed to establish the RR of drivers operating under its influence. Other results to emerge from numerous studies over this period are little more than suggestive. The epidemiologists' common failure is understandable. It is commonly thought that the prevalence of THC use in the normal population can only be determined from the drug's detection in blood samples provided by drivers at roadside checkpoints. With no means to compel or convince normal motorists to provide control data, epidemiologists have had to confine their attention to drivers from whom blood samples can be obtained after their admittance to hospitals as the result of injuries sustained in crashes. Thus, epidemiologists have only been able to measure the prevalence of THC use among injured drivers. Some epidemiologists have found a relatively high prevalence of THC in a limited geographical area, and others, significantly more THC users among drivers deemed responsible for crashes than apparently innocent victims. However, these results are equivocal. A high prevalence among injured drivers in one particular area might simply reflect a high usage prevalence among the local population. Methods for assigning responsibility have differed widely and those relying solely on police judgments may reflect their biases; e.g., suspected drug users may more often be judged responsible than is actually the case. Moreover, epidemiologists have always had to contend with a serious confounding factor; i.e., the simultaneous presence of alcohol in the majority of drivers who test positive for THC.

Surveys conducted in widely separated localities have generally revealed the presence of THC in between 4 and $12 \%$ of drivers who sustained injury or death in crashes (Cimbura et al, 1980, 1982; Terhune, 1982; Chesher \& Starmer, 1983; Donelson et al, 1985; Garriott et al, 1986; Daldrup et al, 1987; McClean et al, 1987). Occasionally, higher values have been reported for groups of, predominately, young males operating in one or another large American city (Williams et al, 1985; Soderstrom et al, 1988; Budd et al, 1989). Although 


\section{Marijuana / Alcohol Driving Study}

the prevalence of THC users in the general driving population was assumed to be lower in almost every case, these data can not be accepted as evidence showing that THC was responsible for the crashes. The reason is that alcohol, usually in concentrations associated with a high crash risk, was also found in at least $50 \%$, and sometimes as many as $90 \%$, of the same drivers. The latest and largest of the postmortem surveys (Terhune et al, 1992) came closest to discriminating among the separate and combined effects of THC and alcohol on crash risk. It involved a sample of 1,882 fatally-injured drivers from seven widely separated American States during 1990-91. Drug-free drivers comprised $42.1 \%$ of the sample, and those showing the presence of alcohol, $51.5 \%$. THC was found in only $4.3 \%$ and among them, three-quarters tested positive for alcohol as well. The investigators undertook two different analyses for inferring causal relationships between these drugs and crashes. First, they compared responsibility rates of subgroups using each drug separately and in combination with that for the drug-free group. Responsibility in this case was assigned by trained encoders using a standardized procedure for evaluating police reports. Drug-free drivers were held responsible for $67.7 \%$ of their crashes. The responsibility rates for drivers showing only the presence of alcohol depended upon their BACs. For those with BACs below $0.10 \mathrm{~g} / \mathrm{dl}$ it was $75.8 \%$, and for those at or above that level, $93.9 \%$. Drivers showing only the presence of THC were $57.9 \%$ responsible; i.e., less often than drug-free drivers, albeit not significantly. However, the group showing the combined presence of THC and alcohol in any concentration at all, were held responsible for $94.6 \%$ of their crashes. This rate differed significantly from the drug-free drivers' though not from the group's with the highest BACs. The second analysis was for calculating the relative crash risk (RR) of each subgroup whose number was sufficient for providing a reliable estimate. "Nonresponsible" drivers in the sample were defined as the control group, following the assumption that they were representative of the general driving population with respect to drug and alcohol prevalence. The investigators were aware that their definition of the control group is unconventional and urged caution in interpreting the results. But as they said, those results were certainly "suggestive." Relative to drug-free drivers whose RR was defined as 1.0 , those showing $\mathrm{BAC}<0.10 \mathrm{~g} / \mathrm{dl}$ operated with a $\mathrm{RR}=1.2$. Drivers operating with $\mathrm{BAC} \geq 0.10 \mathrm{~g} / \mathrm{dl}$ did so with $\mathrm{RR}=6.5$. Strikingly, drivers operating with $\mathrm{THC}$ and any $B A C$ had a $R R=11.9$. Unfortunately, only 19 fatally injured drivers were found with only THC in their blood, too few for estimating the RR.

Terhune et als results suggest a particularly dangerous synergistic (i.e., multiplicative) interaction between THC and alcohol but they carefully avoided drawing that conclusion. Their data were insufficient for confirming the impressions that drivers using only THC were less likely than drug-free drivers to be responsible for fatal crashes; and, that those showing the presence of both THC and alcohol were more likely to be responsible than others using

alcohol alone. The data were also insufficient for determining whether the combined drug 


\section{Marijuana / Alcohol Driving Study}

users' risk of fatal crash involvement increased more rapidly as a function of BAC than for the drivers using alcohol alone. Besides, their risk estimates are questionable since there is reason to doubt that "non-responsible" fatally injured drivers are representative of the driving population in general: some of them may have been responsible in the sense of failing to avoid the situations where the crashes occur. All doubts would have been avoided if the control group was comprised of drivers who were not involved in crashes. But this postmortem survey, like all before it, lacked the essential controls. Not surprisingly, the investigators concluded that it would be pointless to undertake even larger postmortem surveys in an effort to define THC's role in crash causality. Instead they recommended crash surveys involving the more numerous injured but surviving drivers whose accounts of antecedent events would better enable the assignment of responsibility; and, experimental studies designed specifically to show THC and alcohol effects, alone and in combination.

Numerous experimental studies have already been undertaken for that purpose (reviews: Chesher 1995; Robbe, 1994). Most are of limited relevance in the present context since the laboratory psychomotor tests they employed were short and relatively simple, bearing almost no resemblance to actual driving. It is only worth mentioning that no study measuring the separate and combined effects of up to three doses of both alcohol and THC has ever shown that the drugs' effects are more than additive. That is, their combined effects were essentially no greater than the sum of changes that each drug produced separately. Chesher noted, however, that the drugs' impairing effects in some laboratory tasks have differed qualitatively. Thus, the combination might simultaneously degrade different mental functions that independently affect performance in complex real-life tasks. That being the case, one might expect the simuitaneous effects of THC and alcohol to seriously degrade complex performance, even if those effects are not synergistic in the classic pharmacological sense.

Driving is probably the most complex psychomotor task undertaken by ordinary individuals on a routine basis. It is difficult to conceive, much less simulate, every situation that confronts drivers. At best, tests for measuring drugs' effects in driving simulators, over a closed-course driving terrain or on real roads and in normal traffic, can measure only a few aspects of total driving behavior. Nonetheless, it would seem that the closer they approach reality, the better their likelihood of measuring the effects that cause crashes. This assertion has never been proven but its general acceptance is evident from the gradual development of more realistic tests, both for use in simulators and on the road.

Smiley et al (1981), conducted the first study of THC and alcohol effects in an interactive driving simulator. That system responded to the operator's control inputs by modifying its displayed visual imagery according to normal vehicle dynamics, though on a fixed base. The simulated tasks contained in a 45-min. scenario included driving on straight and curved road segments, following a vehicle and passing when gaps in the oncoming traffic permitted, 


\section{Marijuana / Alcohol Driving Study}

changing the route in response to navigational information on signs and avoiding obstacles that suddenly appear on the roadway. A visual choice reaction time was also superimposed on driving. Three groups of marijuana users smoked cigarettes containing 0,100 and $200 \mu \mathrm{g} / \mathrm{kg}$ THC on two occasions per dose, once with and once without alcohol. The quantity of alcohol consumed varied between groups to reach blood concentrations of 0.00 , 0.05 and $0.08 \mathrm{~g} / \mathrm{dl}$, respectively. To ensure high motivation, good driving was rewarded and blatant errors, such as crashes, were penalized financially. The test began $15 \mathrm{~min}$. after the cessation of smoking. Both THC doses increased lateral position variability and the highest dose increased speed variability during curve following. Both THC doses increased headway variability, and the highest, lateral position variability during car following. Both caused the subjects to ignore navigational information. The high dose caused the subjects to hit roadway obstacles more often and to react more slowly in the subsidiary task than the placebo. Yet both THC doses caused the subjects to drive in a more conservative manner. They maintained a longer headway while car following, refused more opportunities to pass, and when they did, began this maneuver at a greater distance from the approaching vehicle. Alcohol's effects in this study were generally not significant. There were also no significant interactions between the drugs' effects on any performance measure.

Stein et al (1983) conducted two studies of alcohol and marijuana effects using a similar driving simulator and test scenario, lasting $15 \mathrm{~min}$. Both studies followed a 2 (alcohol) $\times 3$ (THC) cross-over design. Alcohol placebo and alcohol sufficient for producing a BAC of $0.10 \mathrm{~g} / \mathrm{dl}$ were given in both. The THC doses were 0 (placebo), 50 and $100 \mu \mathrm{g} / \mathrm{kg}$ in the first and 0,100 and $200 \mu \mathrm{g} / \mathrm{kg}$ in the second. As opposed to the lack of alcohol effects in the earlier simulator study, these two showed alcohol's expected, significantly adverse effects on practically every performance measure. Again in contrast to the earlier study, THC had almost no significant effects. The rather benign exception was that the subjects drove at a lower speed after the highest THC dose. The combination of drugs produced no consistent signs of a pharmacodynamic interaction affecting performance. It did, however, produce a marked rise in inter-subject performance variability, suggesting that some individuals might have been severely affected. The combination with the highest THC dose also produced significantly more "accidents" than alcohol did alone.

Four studies have followed the alternative approach of testing alcohol's and THC's effects on vehicle handling performances during staged maneuvers on a terrain closed to normal traffic (Casswell 1997; Attwood 1981; Smiley et al, 1986; Peck et al, 1986). Except for the last, these studies seem of minor importance. The driving tests varied from one to the other making their results difficult to compare. Casswell and Attwood treated small groups of male volunteers, 13 and 8 , respectively, in cross-over designs with higher doses of each drug separately than when both were given in combination. THC doses were very low in all cases $(<90 \mu \mathrm{g} / \mathrm{kg})$. Smiley et al administered more representative THC doses (100 and $200 \mu \mathrm{g} / \mathrm{kg})$ 


\section{Marijuana / Alcohol Driving Study}

alone and in combination with alcohol sufficient for achieving a BAC of $0.05 \mathrm{~g} / \mathrm{dl}$, and also a higher dose of alcohol alone $(B A C=0.08 \mathrm{~g} / \mathrm{dl}$ ), but to separate groups of 9 men. So the statistical power of their design was not greater than the others'. In any case the effects of THC and alcohol alone, and in combination, were modest in every study and no sign of a synergistic interaction was observed.

Peck et al's study was superior in most respects. It too followed a parallel group design with 21 male participants in each one. They were respectively treated with double placebo, alcohol $(B A C=0.08 \mathrm{~g} / \mathrm{dl})+$ marijuana placebo, alcohol placebo + THC $19 \mathrm{mg}$, and both drugs combined. If these subjects could have consumed the entire THC dose, on the average it would have been about $270 \mu \mathrm{g} / \mathrm{kg}$. But considering the residual left after smoking, the actual average dose was probably closer to $250 \mu \mathrm{g} / \mathrm{kg}$. The subjects were tested in four complete replications of test battery at $1-\mathrm{hr}$ intervals beginning shortly after dosing. Ratings of their proficiency were obtained from accompanying driving licensing examiners, from observers stationed at points along the test route and from traffic police officers who followed the subjects' vehicle in a patrol car. A computerized system recorded the subjects' control movements and the vehicle's speed and lateral position relative to course delineation. A risk acceptance test was included for measuring the subjects' willingness and ability to drive through gaps that were slightly wider or narrower than the vehicle. Other tests involved stopping in response to signals, making a forced lane change and driving through a chicane. Several hundred performance variables were recorded and tested preliminary for selecting those that twice discriminated between treatment effects with a "significance" level of at least $\mathrm{p} \pm 0.25$ in separate battery repetitions. Only 12 variables were found significant according to this unusually liberal criterion. These were taken together into, first discriminant analysis for testing the global significance of the drugs' effects, then a canonical analysis for separately testing the main effects of each drug separately and of their interaction. The global effect was significant in all trials. The separate effects of both drugs were also significant but not their interactive effect, leading to the conclusion that the effects were additive. Yet they were modest indeed. The only sign that these relatively high doses of THC and alcohol impaired driving performance to a practically relevant degree came from the reports of the following police officers. They said they would have stopped $60 \%$ of the drivers treated with both drugs if they had observed them behaving the same way in real-life. The corresponding judgments for groups treated with alcohol and THC alone were $50 \%$ and $32 \%$, respectively. But the officers also said they would have stopped $15 \%$ of the placebo subjects. Either all subjects were exceptionally poor drivers or the officers were unusually critical. Perhaps they were so critical because they knew that the drivers under observation were likely ( $75 \%$ chance) to have taken drugs. 
In short, previous driving simulator and closed-course studies have failed to confirm what epidemiologists' data suggest, i.e., that alcohol and THC interact synergistically to produce greater impairment than the sum of the changes that each drug produces separately. Yet with the methodological shortcomings of particular studies and the general lack of test realism afflicting all, it can not be said that their failure to measure a synergistic effect is particularly convincing.

The present study represents another attempt to empirically determine the separate and combined effects of THC and alcohol on driving. It differs from its predecessors by employing standardized tests for objectively measuring the drugs' effects on driving performance in the natural environment; i.e., on real roads in normal traffic. The same approach has already been applied for assessing the separate effects of alcohol (Louwerens et al, 1987) and THC (Robbe and O'Hanlon, 1993), as well as those of medicinal drugs in a series of more than 50 studies (reviews: O'Hanlon 1984; O'Hanlon et al, 1986, 1995: O'Hanlon \& Ramaekers 1995). It is hoped that the present study, and one more to follow, will conclusively demonstrate whether the drugs' combined effects are additive or synergistic, and how much in either case. 
Marijuana / Alcohol Driving Study

\section{METHODS}

\subsection{Subjects}

Male and female volunteers were solicited by an advertisement in the newspaper of the Maastricht University. It described the general nature of the study and provided a telephone number to call for further information. Respondents were preliminarily screened to determine if they fulfilled the inclusion criteria: current use of both alcohol and marijuana with respective frequencies of once per week and once per month, but neither daily; possession of a valid driving license; driving experience of at least $1000 \mathrm{~km} / \mathrm{yr}(620 \mathrm{mi} / \mathrm{yr})$ over the previous three years; willingness to comply with certain restrictions of daily living activity (below); and, willingness to provide written informed consent. Those who apparently satisfied all criteria were sent Information for Volunteers, which completely described the study and its requirements, as well as questionnaires regarding personal medical history and experience with alcohol and drugs. Volunteers wishing to continue resumed contact for arranging a medical screening interview. The latter comprised a review of the completed questionnaires, a physical examination, a standard 12-lead ECG examination and the submission of blood and urine samples for routine clinical laboratory determinations. Fractions of the urine samples were retained and assayed qualitatively, on site, for drugs of abuse - amphetamines (including MDMA, called "ecstasy"), barbiturates, benzodiazepines, cannabinoids, cocaine and opioids. Urine from females was also assayed for $\beta-H C G$ to indicate pregnancy. Volunteers were excluded on the basis of results showing any of the following: history or evidence of drug or alcohol abuse or dependency; history of psychiatric or organic brain disorders; history or overt signs of serious cardiovascular, respiratory, renal, hepatic, metabolic or neuromuscular disorders; necessity for the chronic use of any systemic medication, except oral contraceptives; current use of any prescribed psychoactive medication; the presence of any drug of abuse in urine, besides cannabinoids; and for females, pregnancy or any reasonable possibility that pregnancy could occur during participation in the study. One unusual exclusion criterion was added by local law enforcement authorities as a condition for their approval of the study: volunteers having any record of arrests for drug trafficking were to be excluded. For this purpose the Chief District Attorney for the City of Maastricht reviewed a list of volunteers' names with their knowledge and consent. The District Attorney neither retained nor copied the list and he guaranteed no legal consequences for the individuals concerned. No volunteer was excluded by this procedure but common knowledge that it would be applied might have dissuaded some individuals from ever volunteering.

Eighteen subjects, 9 men and 9 women were selected. They ranged in age from 20 to 28 years (mean $\pm S D, 22.7 \pm 2.1)$. All satisfied the inclusion criteria for driving experience with 


\section{Marijuana / Alcohol Driving Study}

one exception; i.e., a woman had been licensed to drive for only 20 months before enrolling. She was allowed to enter the study for achieving a better balance between genders. The longest any subject had held a driving license before enrolling in the study was 9.5 yr. For the group as a whole, mean \pm SD driving experience was $4.3 \pm 2.2$ yr. The subjects declared their alcohol drinking frequency was from 1 to 30 glasses of wine or beer per week (14.2 \pm 8.8$)$; and their marijuana smoking frequency from 1 to 12 times per month $(2.3 \pm 2.3)$. All said that they occasionally used both drugs in combination and admitted having driven at least once under the influence of each one separately. However, only three admitted to having driven under the combined influence of both. Subjects were paid NLG 650 (ca. US\$ 335) upon completion of the study.

\subsection{Legality and Ethics}

The study's protocol was reviewed and approved in sequence by the District Attorney and the standing Medical Ethics Committee of Maastricht University. Subjects were treated according to the international convention governing drug studies with human volunteers; i.e., the Declaration of Helsinki (1964), and its subsequent amendments.

\subsection{Design, Doses and Administration}

The study followed a balanced, 6-way ( $2 \times 3$ factorial) observer- and subject-blind, placebo controlled, cross-over design. Treatment orders were randomly assigned from those residing in three, 6x6, Williams Squares.

Subjects began treatments by drinking alcohol or alcohol placebo. They continued by smoking marijuana placebo or marijuana delivering THC in doses of 100 or $200 \mu \mathrm{g} / \mathrm{kg}$. All six combinations of alcohol and THC were consumed by all subjects on separate occasions. These treatments are respectively designated as shown in Table 2-1.

Table 2-1 Abbreviations of treatment conditions.

\begin{tabular}{lllllll}
\hline Treatment condition & OO & OT $_{1}$ & OT $_{2}$ & AO & AT $_{1}$ & AT \\
\hline Alcohol & placebo & placebo & placebo & alcohol & alcohol & alcohol \\
THC & placebo & $100 \mu \mathrm{g} / \mathrm{kg}$ & $200 \mu \mathrm{g} / \mathrm{kg}$ & placebo & $100 \mu \mathrm{g} / \mathrm{kg}$ & $200 \mu \mathrm{g} / \mathrm{kg}$ \\
\hline
\end{tabular}

Alcohol dosing was designed to achieve a peak BAC of $0.06-0.07 \mathrm{~g} / \mathrm{dl}$ before smoking and $0.04-0.05 \mathrm{~g} / \mathrm{dl}$ during the driving tests. To achieve this, subjects ate two sandwiches while drinking the initial dose; i.e., $0.6 \mathrm{~g} / \mathrm{kg}$ of "pure" $(99.8 \%)$ ethanol mixed with orange juice to a volume of $300 \mathrm{ml}$ and flavored with Grand Marnier essence for masking purposes. This 


\section{Marijuana / Alcohol Driving Study}

was accomplished within $30 \mathrm{~min}$. Subjects' BACs were monitored at $10 \mathrm{~min}$. intervals for 30-60 min. after the cessation of drinking using a Lion S-D4 Breath Alcohol Analyzer. Those failing to achieve the expected peak BAC were given a booster dose of $0.05-0.2 \mathrm{~g} / \mathrm{kg}$ in the same proportion to the mixer, whereas the others were given the mixer alone. A second booster dose was given midway through the driving tests in almost all cases for sustaining the desired BAC. Flavored orange juice was given at the same times and in approximately the same volumes in the placebo alcohol conditions. Smoking followed the cessation of the first alcohol dose by $60 \mathrm{~min}$. and continued for the following $10 \mathrm{~min}$. The cigarettes were prepared beforehand for each individual from stock provided by the US National Institute on Drug Abuse. Originally, placebo cigarettes (i.e., containing marijuana leaf from which THC had been removed by ethanol extraction) and those containing the drug were all $85 \mathrm{~mm}$ in length and $25 \mathrm{~mm}$ in circumference, weighing about $800 \mathrm{mg}$. Cigarettes with THC concentrations of $2.2 \%$ and $3.95 \%$ were respectively used for providing 100 and $200 \mu \mathrm{g} / \mathrm{kg}$ doses. These were cut to provide lengths appropriate for the subjects' weights. Placebo cigarettes were similarly shortened. All were humidified over a saturated sodium chloride solution at $20^{\circ} \mathrm{C}$ for $24 \mathrm{hr}$ before consumption. Subjects smoked them as completely as possible through a plastic holder in their customary fashion.

\subsection{Procedures}

Two subjects were tested per day. They were transported by an investigator to and from the sites for treatment and testing. After arriving at 19:00 h, subjects yielded breath and urine samples for confirming their compliance with prohibitions against prior use of alcohol and drugs (below). Drinking, followed by smoking, proceeded until 20:40 hr. Thereupon the pair of subjects was taken to the origin of the driving tests. There were two tests (below) that were performed twice per session, all during darkness and in actual traffic. Each member of the pair of subjects began performing a different test. One departed from the origin 2 min. before and the other $2 \mathrm{~min}$. after 21:00 hr. Both proceeded with their initial test assignments while driving over the same $40 \mathrm{~km}(24.8 \mathrm{mi})$ highway segment until arriving at the highway exit that marked the terminal, where the first subject awaited the second. When that occurred, their test assignments reversed. The first subject resumed driving at $21: 30 \mathrm{~h}$, crossed and re-entered the highway traveling in the opposite direction than before while performing the opposite test. The second did the same after a $4 \mathrm{~min}$. delay. Both paused for $15 \mathrm{~min}$. after returning to the origin. Their BACs were monitored and a booster alcohol dose was given, if needed. Beginning around $22: 15 \mathrm{~h}$, the subjects drove through another circuit while repeating the same series of tests as before. Subjects rated their levels of intoxication at the beginning and end of the entire sequence, and the quality of their performance, at the end of each driving segment. An instructor accompanying the subjects similarly rated their 
Marijuana / Alcohol Driving Study

performance at these times. The same subjects always undertook the two driving tests in the same order.

Successive test sessions were ordinarily scheduled for particular subjects at weekly intervals. They were forbidden to smoke marijuana or hashish outside of the study, or to take any other illicit drug, from 7 days before their first session until the conclusion of the last. They were told that the detection of any drug in urine samples provided at the beginning of a session would cause their immediate dismissal. They were similarly forbidden to drink alcohol for $24 \mathrm{hr}$ before sessions. They were instructed to retire for and arise from sleeping at normal times and to avoid strenuous physical activities over the day before sessions. Consumption of beverages containing caffeine and of solid food was prohibited for $2 \mathrm{hr}$ before session. And, smoking nicotine containing cigarettes was prohibited during the sessions. Finally, the subjects were prohibited from participating in another biomedical investigation, particularly if it involved drug taking; and, they were required to report the use of any systemic medication taken for personal reasons.

\subsection{Driving Tests and Rating Scales}

General Driving Procedures. Subjects operated a specially instrumented Volvo 240 GL station wagon accompanied by a licensed driving instructor having access to redundant vehicular controls from his position in the front passenger's seat. They were told that the instructor's primary role was to ensure test safety but that they would be held responsible under Dutch Law for any collisions that might occur. They were further told that they were legally responsible not to undertake a test and to stop any in progress, if in doubt concerning their ability to drive safely. They were advised that the instructor could require them to bring the vehicle to: a halt on the road shoulder if in his opinion their performance was becoming unsafe. No penalties or censure were attached to the subject's decision to avoid or stop driving. Subjects were trained to perform both driving tests in one complete rehearsal of all procedures they would later encounter after drug treatments. Their performance during training rides was evaluated by: the instructor and judged normal in every case. Data recorded during treatment sessions were edited and reduced by assistants using interactive computer programs. These personnel were not informed of the nature of the treatments given on particular occasions.

Road Tracking. The standardized version of this test (O'Hanlon, 1984) involves driving over a $100 \mathrm{~km}(62 \mathrm{mi})$ highway circuit with a short interruption for reversing the direction of travel at the mid-point. It normally lasts about one hour: The test was modified for the purposes of the present study. It was given in two, $25 \mathrm{~min}$. parts, separated by an interval of $45 \mathrm{~min}$ Otherwise the test followed the standard model. It was given over that segment of the 4-lane, divided, highway (A2) running north/south between the cities of Maastricht and 


\section{Marijuana / Alcohol Driving Study}

St. Joost. The subject entered the highway and accelerated to achieve a speed of $100 \mathrm{~km} / \mathrm{h}$ $(62 \mathrm{mph})$ in the right (slower) traffic lane. His/her instructions were to maintain that speed and a steady lateral position between the delineated lane boundaries over the entire segment. The subject was only allowed to deviate from these instructions for overtaking a slower vehicle traveling in the same traffic lane. Upon arrival at the end of the segment, the subject drove off the highway at the designated exit, parked the vehicle and awaited the next scheduled activity. The vehicle contained systems for recording speed and lateral position. The former originated from an electromagnetic sensor and pulse generator attached to the drive wheels. Pulses were converted to an analog voltage, proportional to speed between 0 and $120 \mathrm{~km} / \mathrm{h}$. An electro-optical lateral position sensor was rack-mounted in protective housing over the left rear corner of the vehicle. Its lens acquired an image of road surface directly behind the vehicle, in effect focusing a 3-m band running at right angles to the direction of travel on a linear array of 256 capacitor-coupled photodiodes. Luminance from the left lane-line was normally the greatest falling upon the array, thus causing the most rapid discharge of one particular diode-capacitor at any given moment. The position of that diode was determined relative to a calibrated null-point by rapid $(>100 \mathrm{~Hz})$ electronic scanning. The difference was used to generate an analog voltage proportional to the distance the vehicle was to the right or left of lane-center. Full scale values were obtained when the vehicle was $\pm 1.5 \mathrm{~m}$ from lane-center. Taking into account both the asymmetric location of the sensor and the vehicle's width $(1.6 \mathrm{~m})$, maximum readings occurred when it was $0.38 \mathrm{~m}$ onto the road shoulder or into the adjacent traffic lane. Analog signals were digitized by Burr-Brown data acquisition cards using Labtech Notebook Software at a rate of $4 \mathrm{~Hz}$. These data were time-coded and filed on hard-disk in an on-board computer. Files were copied on diskette and edited off-line to remove parts recorded during passing maneuvers and when the lateral position signal was absent or distorted by noise. Data were preliminarily analyzed by $5-\mathrm{km}$ segments to yield mean and standard deviation values of both parameters; and also, intervals when the vehicle was traveling outside of the assigned traffic lane. The values finally recorded as tests scores over each segment were the following: mean speed and lateral position (MSP, MLP); the square roots of pooled speed and lateral position variances as estimates of each parameter's standard deviation (SDSP, SDLP); and, the relative time out of lane (TOL). SDLP was the primary dependent variable. Normative data provided by more than 600 healthy volunteers $(<65 \mathrm{yr})$ who undertook the standard test under placebo control conditions in the Institute's previous studies have shown that SDLP follows a log-normal distribution with $\mu \pm \sigma$ of approximately $3.06 \pm 0.19 \log _{e} \mathrm{~cm}$ units. Thus, about $99 \%$ of the distribution fell between 12.5 and $35.5 \mathrm{~cm}$; i.e., the normal limits. SDLP scores from repeated measurements on the same subjects under control conditions are very reliable; i.e., test-retest coefficients of correlation have typically varied between 0.7 and 0.9 for groups of 16-24 individuals (O'Hanlon et al, 1986, 1995). Moreover, SDLP was sensitive to the effects of all sedating drugs so far studied; e.g., to alcohol in blood 


\section{Marijuana / Alcohol Driving Study}

concentrations as low as $0.035 \mathrm{~g} / \mathrm{dl}$ (Vuurman $e t$ al, 1996) and to THC in doses at or above $100 \mu \mathrm{g} / \mathrm{kg}$ (Robbe \& O'Hanion, 1993).

Car Following. The second test was developed in a pilot study (Brookhuis et al, 1987) and has been repeatedly applied in progressively improving versions (Robbe \& O'Hanlon, 1993; Ramaekers et al, 1994; Vuurman et al, 1996). It measures the driver's ability to perceive changes in an immediately preceding vehicle's speed and react in a manner maintaining a constant headway. The car following test was likewise given in two parts lasting about $25 \mathrm{~min}$. apiece and separated by an interval of $45 \mathrm{~min}$. The test involves two vehicles traveling in tandem, the first operated by an investigator and the second by the subject. They entered the highway and accelerated together to achieve a constant speed of $100 \mathrm{~km} / \mathrm{h}$ $(62 \mathrm{mph})$. The subject was instructed to drive $50 \mathrm{~m}(164 \mathrm{ft})$ behind the preceding vehicle. The instructor defined this distance for the subject at the beginning of each part of the test but did not correct his/her headway again before coming to the end. Once the subject's headway had stabilized, the investigator operating the preceding vehicle executed a series of speed changes interpolated between $0.5-5.0 \mathrm{~min}$. of constant driving. Speed changes in alternating directions were controlled by computer manipulation of a conventional cruisecontrol system. In each case the vehicle accelerated or decelerated in a constant manner causing its speed to rise or fall by $15 \mathrm{~km} / \mathrm{h}(9.3 \mathrm{mph})$ over $33 \mathrm{sec}$. The subject's task was to follow this change as quickly and as accurately as possible by controlling his/her own vehicle's speed using the accelerator pedal. Depending on the traffic, the number of maneuvers during each repetition of the test varied between 4 and 10 in each direction (i.e., acceleration and deceleration), except in one case where only one maneuver was undertaken. The preceding vehicle's speed was continuously measured and transmitted via telemetry to a receiver on the following vehicle. A discrete signal to indicate the beginning of each maneuver was inserted in that FM transmission. The transmission was demodulated and digitally encoded at $4 \mathrm{~Hz}$ in a computer file along with the parallel record of the following vehicle's speed. Headway was also measured directly by a ranging laser system (Sick DSE 2000) from a transmitter/receiver located in the center of the following vehicle's grill. This system emitted $4.5 \mathrm{~ms}$ pulses at $40 \mathrm{~Hz}$ and registered their reflections from a solid $1.5 \times 1.0$ $\mathrm{m}$ screen mounted vertically on the back of the preceding vehicle. The phase angle between each emission and reflection was measured and converted to an analog voltage, proportional to distance. This signal was sampled, digitized and stored in the same manner as the others. Distance recordings were occasionally incomplete owing to misalignment of the vehicles. Missing data were estimated based on the observed differential vehicle speeds. Data were analyzed off-line using an interactive computer program. The program identified the initiation of each maneuver and when the preceding vehicle's speed began and ended its linear change. Usually the following vehicle's speed rose or fell in parallel after the subject recognized the change. In these cases, the program automatically recorded the driver's reaction time (RT) when the speed of his/her vehicle had changed by $2 \mathrm{~km} / \mathrm{h}$ in the correct 
direction. Sometimes however, the driver equivocated at the beginning of the maneuver causing the vehicle's speed to vary erratically. In these cases, the analyst extrapolated backward in time from where the subject's speed was clearly in linear ascent or decent to $2 \mathrm{~km} / \mathrm{h}$ higher or lower than the last reversal. The difference in time between that point and the beginning of the preceding vehicles speed change was taken as the subject's RT. The distance separating the vehicles at the moment of the preceding vehicle's speed began to change was measured as the initial headway. Parameters measured during maneuvers were mean, standard deviation, minimum and maximum headway $\left(\mathrm{H}_{\mathrm{M}}, \mathrm{H}_{\mathrm{SD}}, \mathrm{H}_{\mathrm{MN}}, \mathrm{H}_{\mathrm{MAX}}\right)$. $\mathrm{RT}$ and $\mathrm{H}_{S D}$ are the most important variables, the former measuring the latency of the driver's initial response and the latter, the precision of headway maintenance after that response. $\mathrm{H}_{M}$ is normally measured for possible statistical adjustment of $\mathrm{H}_{S D}$ should $\mathrm{H}_{M}$ vary between conditions in a given experiment. $\mathrm{H}_{\mathrm{MAX}}$ and $\mathrm{H}_{\mathrm{MNN}}$ were measured for the first time in this study for exploratory purposes.

Subjective Rating Scales. Subjects rated the degree to which they felt "under the influence" of the given drug or combination on a continuous $100-\mathrm{mm}$ scale. It ranged from "not at all" to "the most $I$ have ever experienced." This rating was made just before driving and immediately after its final conclusion. They also rated the quality of their immediately preceding driving performance after each test segment on a scale from 1 to 10 in 0.25 unit steps. Subjects were told to rate their performance in the manner traditionally used in the Dutch school system. The score of 10 means "perfect." Scores of 6 and above are "passing" to "excellent." And, scores below 6 are "failing" to progressively diminishing degrees. The accompanying driving instructor independently rated the subjects' performance at the same times on the same scale and in the same manner.

\subsection{Statistical Analysis}

SDLP, the primary dependent variable, was analyzed in sequential steps. The first was a check for Period and $1^{\text {st }}$-Order Carryover effects using the SAS (6.09) General Linear Model (GLM) procedure with Type I sums of squares. Then Multivariate Analysis of Variance (MANOVA) was applied according to the SPSS/PC+ procedure for repeated measures to test the main effects of Alcohol, THC, Repetitions and their interactions. Data entering this analysis were weighted by orthogonal polynomial coefficients so that the linear and quadratic components of the THC effect over doses, and the same in interaction with alcohol, could be separately tested. Finally, univariate (i.e., ANOVA) mean-pair contrasts between values recorded in the double-placebo condition and every other one were made using pooled error variance and the Sequential Bonferroni $\mathrm{p}_{\alpha}$ adjustment for multiple comparisons (Overall \& Rhoades, 1985). MLP, MSP and SDSP were analyzed the same way. TOL was analyzed the same way after $\log _{10}$ transformation to adjust for the expected 
skew in the raw data. All maneuvers performed by subjects in both repetitions of the $\mathrm{Car}$ Following Test were analyzed to yield average values of $R T, H_{M}$ and $H_{S D}$, by subject and condition. Average values of $\mathrm{H}_{\mathrm{MAX}}$ were calculated for acceleration maneuvers, and of $\mathrm{H}_{\mathrm{MIN}}$, for deceleration maneuvers. The same analyses were planned for these parameters but circumstances forced their analysis by other means (below). Subjective parameters were analyzed by MANOVA for the effects of Alcohol, THC, Repetitions and their interactions. The between-groups factor of Rater was added to assess differences between subjects' and instructors' ratings of driving quality. 


\section{RESULTS}

\subsection{Adjustments for Missing Data}

Table 3-1 lists the tests which failed to yield useful data by condition, repetition within condition and subject. Data were missing for four (1.85\%) planned repetitions of the Road Tracking Test and $25(11.6 \%)$ of the Car Following Test. One of the former could not be undertaken by a subject whose BAC exceeded the acceptable limit at the time. The other failures to record data in the Road Tracking Test were attributable to operator error. These missing data were replaced in the planned analyses by scores recorded during the other repetition of the test on the same nights.

Table 3-1 Road Tracking and Car Following tests which failed to yield useful data by condition, repetition within condition and subject (for definition of treatment conditions, see Table 2-1).

\begin{tabular}{|c|c|c|c|c|c|}
\hline \multicolumn{3}{|c|}{ ROAD TRACKING } & \multicolumn{3}{|c|}{ CAR FOLLOWING } \\
\hline COND. & REP. & SUB. & COND. & REP. & SUB. \\
\hline $\mathbf{O T}_{2}$ & 1 & 02 & 00 & 1 & 16 \\
\hline AO & 1 & 12 & 00 & $1 \& 2$ & 10 \\
\hline $\mathbf{A T}_{2}$ & 1 & 15 & $\mathbf{O T}_{1}$ & 1 & 09 \\
\hline \multirow[t]{15}{*}{$\mathbf{A T}_{2}$} & 2 & 18 & $\mathbf{O T}_{2}$ & $1 \& 2$ & 11 \\
\hline & & & $\mathbf{O T}_{2}$ & $1 \& 2$ & 18 \\
\hline & & & AO & 1 & 04 \\
\hline & & & AO & 1 & 13 \\
\hline & & & AO & 1 & 14 \\
\hline & & & AO & $1 \& 2$ & 02 \\
\hline & & & AO & $1 \& 2$ & 08 \\
\hline & & & $\mathbf{A} \mathbf{T}_{1}$ & 2 & 01 \\
\hline & & & $\mathbf{A T}_{1}$ & 1 & 10 \\
\hline & & & $\mathbf{A T}_{1}$ & 1 & 11 \\
\hline & & & $\mathbf{A T}_{1}$ & $1 \& 2$ & 06 \\
\hline & & & $\mathbf{A} \mathbf{T}_{2}$ & 1 & 07 \\
\hline & & & $\mathbf{A} \mathbf{T}_{\mathbf{2}}$ & 2 & 11 \\
\hline & & & $\mathbf{A T _ { 2 }}$ & 2 & 15 \\
\hline & & & $\mathbf{A T}_{2}$ & $1 \& 2$ & 04 \\
\hline
\end{tabular}

Nearly all failures to record data in the Car Following Test were caused by the subjects' unwillingness or inability to consistently maintain a following distance within the range of the sensor/transmitter system. Though partial data were obtained in some of these cases, they were thought to be too meager for deriving reliable parameter averages. The same procedure for replacing data could not be followed since seven subjects did not provide any useful data in either test repetition after particular treatments. It was not possible to apply 
the planned analyses to car following data. Instead, these data were combined across both test repetitions within each condition to yield average parameter values. They were analyzed in repeated-measures, 2-tailed, $t$-tests for making separate comparisons between double placebo and every drug condition. The Sequential Bonferroni procedure was again used for adjusting the $\mathrm{p}_{\alpha}$ criteria for multiple comparisons within each set of five.

\subsection{Blood Alcohol Concentration (BAC)}

Subjects' BACs generally peaked in the range of $0.04-0.09 \mathrm{~g} / \mathrm{dl}$ (mean $\pm \mathrm{SD}$, $0.067 \pm 0.015 \mathrm{~g} / \mathrm{dl}$ ) within 1 hour after drinking. Those whose peak BACs were below $0.06 \mathrm{~g} / \mathrm{dl}$ were given the first booster dose just before marijuana smoking began at 20:30 hr. Their BACs were again measured before beginning the driving tests at 21:00 hr. Descriptive statistics are given in Table 3-2 for that and subsequent measurements which concluded after driving at $23: 15 \mathrm{hr}$.

Table 3-2 Mean \pm SD, and range, for BACs ( $g / d l$ ) measured in each THC condition at fixed times before, during and after driving tests. Repetitions of the 25-min. driving tests started at 21:00, 21:30, 22:15, and 22:30 hours.

\begin{tabular}{|c|c|c|c|c|c|}
\hline & \multicolumn{5}{|c|}{ TIME (hh:mm) } \\
\hline $\begin{array}{l}\text { THC } \\
(\mu \mathrm{g} / \mathrm{kg})\end{array}$ & 21:00 & $21: 30$ & $22: 00$ & $22: 45$ & $23: 15$ \\
\hline \multirow[t]{2}{*}{0} & $.047 \pm .007$ & $.040 \pm .005$ & $.033 \pm .005$ & $.038 \pm .004$ & $.034 \pm .004$ \\
\hline & $.034-.057$ & $.030-.046$ & $.024-.039$ & $.032-.046$ & $.026-.042$ \\
\hline \multirow[t]{2}{*}{100} & $.048 \pm .007$ & $.044 \pm .005$ & $.039 \pm .006$ & $.040 \pm .005$ & $.034 \pm .004$ \\
\hline & $.036-.064$ & $.035-.053$ & $.028-.051$ & $.028-.045$ & $.028-.042$ \\
\hline \multirow[t]{2}{*}{200} & $.048 \pm .009$ & $.042 \pm .008$ & $.035 \pm .008$ & $.038 \pm .004$ & $.033 \pm .003$ \\
\hline & $.037-.070$ & $.029-.064$ & $.020-.056$ & $.029-.048$ & $.026-.038$ \\
\hline
\end{tabular}

Subjects began driving in every THC condition with mean BACs close to the legal limit of $0.05 \mathrm{~g} / \mathrm{dl}$. Mean BAC declined to about $0.035 \mathrm{~g} / \mathrm{dl}$ over the course of the next hour. The second booster doses were then administered to subjects with BACs below $0.05 \mathrm{~g} / \mathrm{dl}$, which arrested but generally did not reverse the decline. They achieved a mean BAC of about $0.04 \mathrm{~g} / \mathrm{dl} 30 \mathrm{~min}$. later and finished driving with about $0.035 \mathrm{~g} / \mathrm{dl}$. Thus, most of the subjects performed the tests while their BACs fluctuated around $0.04 \mathrm{~g} / \mathrm{dl}$ in a generally declining trend from about 0.05 to $0.035 \mathrm{~g} / \mathrm{dl}$. 


\subsection{Road Tracking}

Standard deviation of lateral position (SDLP) was the study's primary outcome variable. Preliminary analyses of the SDLP data using the SAS General Linear Models Procedure revealed no significant Period or Carryover effects $\left(\mathrm{F}_{5,75}=1.58 \& 1.09\right.$, respectively), thereby allowing the main analysis to proceed as planned. The results are summarized in Table 3-3. Mean ${ }_{ \pm}$SE SDLP values recorded in both repetitions within every treatment condition are shown in Figure 3-1.

Table 3-3 Summary of MANOVA/ANOVA and Mean Pair Comparisons for SDLP (for definition of treatment conditions, see Table 2-1).

\begin{tabular}{|c|c|c|c|}
\hline \multicolumn{4}{|l|}{ MANOVA/ANOVA } \\
\hline EFFECT & $\mathbf{F}$ & df & $\mathbf{p}$ \\
\hline Alcohol (A) & 58.69 & 1,17 & .000 \\
\hline THC: overall & 15.48 & 2,16 & .000 \\
\hline - Linear over doses & 32.41 & 1,17 & .000 \\
\hline - Quadratic over doses & 0.96 & 1,17 & ns \\
\hline Repetitions (R) & 10.49 & 1,17 & .005 \\
\hline AxTHC: overall & 1.59 & 2,16 & ns \\
\hline - Linear over doses & 2.68 & 1,17 & ns \\
\hline - Quadratic over doses & 0.87 & 1,17 & ns \\
\hline RxTHC: overall & 0.04 & 2,16 & ns \\
\hline - Linear over doses & 0.09 & 1,17 & ns \\
\hline - Quadratic over doses & 0.30 & 1,17 & ns \\
\hline AxR & 0.03 & 1,17 & ns \\
\hline AxRxTHC; overall & 1.06 & 2,16 & ns \\
\hline - Linear over doses & 1.06 & 1,17 & ns \\
\hline - Quadratic over doses & 1.30 & 1,17 & ns \\
\hline \multicolumn{4}{|c|}{ PAIR COMPARISONS $(\mathrm{df}=1,85)$} \\
\hline & $\mathbf{F}$ & $\mathbf{p}$ & $\mathbf{p}_{\alpha}$ \\
\hline $\mathbf{O T}_{1}$ vs. $\mathbf{O O}$ & 7.91 & .006 & .025 \\
\hline $\mathrm{OT}_{2}$ vs. $\mathrm{OO}$ & 13.46 & .000 & .0167 \\
\hline AO vs. 00 & 5.19 & .025 & .05 \\
\hline $\mathbf{A T}_{1}$ vs. $\mathbf{0 0}$ & 30.21 & .000 & .0125 \\
\hline $\mathbf{A T}_{\mathbf{2}}$ vs. $\mathbf{0 0}$ & 76.28 & .000 & .01 \\
\hline
\end{tabular}

Subjects drove with the lowest mean SDLP after double placebo (i.e., in OO). The overall effects of both Alcohol and THC were highly significant as was the linear increase in SDLP over THC doses. Every drug treatment significantly elevated SDLP, relative to double placebo, in separate mean-pair comparisons. The main effect of Repetitions was also significant: subjects generally drove with higher SDLPs in the second test repetition than the first. However, the interactive effects of Alcohol, THC and Repetition were uniformly not significant. 


\section{Marijuana / Alcohol Driving Study}

Subjects generally drove with SDLPs below the established normal upper limit of $35.5 \mathrm{~cm}$. Two subjects (\#11 and \#17) exceeded the limit in both $\mathbf{A T}_{1}$ and $\mathbf{A} \mathbf{T}_{2}$. The first subject drove with SDLPs of 40.3 and $40.4 \mathrm{~cm}$ and the second subject with 37.3 and $43.3 \mathrm{~cm}$ in these conditions; i.e., in all cases well beyond the $99^{\text {th }}$ percentile driver in the normal population.

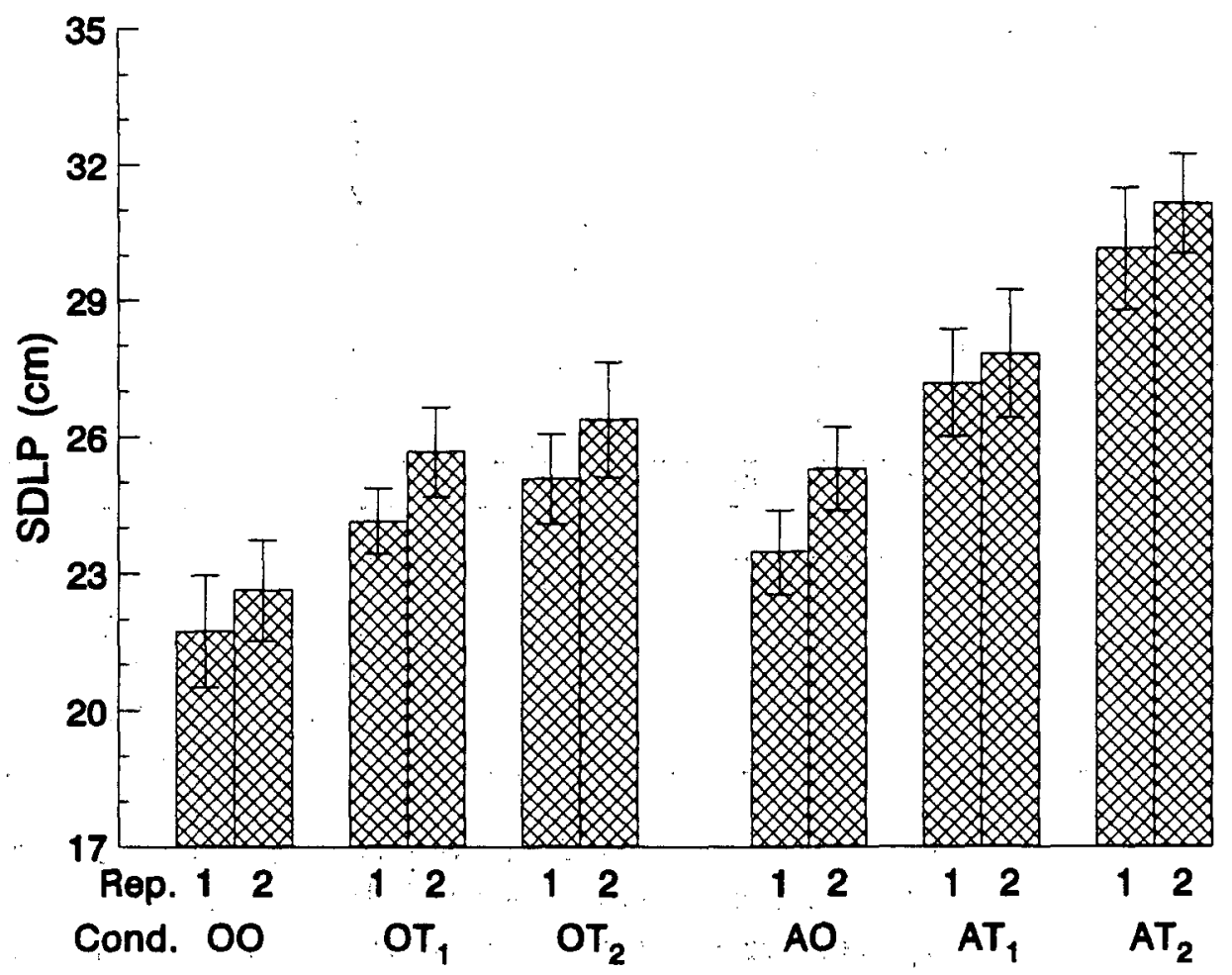

Figure 3-1 Mean ( ${ }_{ \pm}$SE) Standard Deviation of Lateral Position (SDLP, cm) in first and second repetitions of the Road Tracking Test in every condition (for definition of treatment conditions, see Table 2-1).

Time out of lane (TOL) was a secondary but important measure of the subjects' road tracking performance. TOL is a natural nonlinear correlate of SDLP. The former is known to be less sensitive to small drug effects but its rise with large ones has more obvious practical implications. Results of the analysis of $\log _{10}$ TOL are summarized in Table 3-4. 
Marijuana / Alcohol Driving Study

Table 3-4 Summary of MANOVAANOVA and Mean-Pair Comparisons for $\log _{10}$ TOL (for definition of treatment conditions, see Table 2-1).

\begin{tabular}{|c|c|c|c|}
\hline \multicolumn{4}{|l|}{ MANOVA/ANOVA } \\
\hline EFFECT & $\mathbf{F}$ & df & p \\
\hline Alcohol (A) & 17.08 & 1,17 & .001 \\
\hline THC: overall & 4.67 & 2,16 & .025 \\
\hline - Linear over doses & 9.40 & 1,17 & .007 \\
\hline - Quadratic over doses & 0.39 & 1,17 & ns \\
\hline Repetitions (R) & 3.40 & 1,17 & ns \\
\hline AxTHC: overall & 1.23 & 2,16 & ns \\
\hline - Linear over doses & 1.89 & 1,17 & ns \\
\hline - Quadratic over doses & 0.21 & 1,17 & $\overline{\mathrm{ns}}$ \\
\hline RxTHC: overall & 0.14 & 2,16 & ns \\
\hline - Linear over doses & 0.00 & 1,17 & $\overline{\mathrm{ns}}$ \\
\hline - Quadratic over doses & 0.21 & 1,17 & ns \\
\hline $\mathrm{AxR}$ & 0.35 & 1,17 & ns \\
\hline AxRxTHC; overall & 0.35 & 2,16 & $\overline{n s}$ \\
\hline - Linear over doses & 0.05 & 1,17 & ns \\
\hline - Quadratic over doses & 0.56 & 1,17 & ns \\
\hline \multicolumn{4}{|c|}{ PAIR COMPARISONS $(\mathrm{df}=1,85)$} \\
\hline & $\mathbf{F}$ & $\mathbf{p}$ & $\mathbf{p}_{\alpha}$ \\
\hline $\mathbf{O T}_{1}$ vs. OO & 0.06 & ns & .05 \\
\hline $\mathbf{O T}_{2}$ vs. $\mathbf{O O}$ & 3.20 & ns & .0167 \\
\hline AO vs. 00 & 0.71 & ns & .025 \\
\hline $\mathbf{A T}_{1}$ vs. $\mathbf{0 O}$ & 6.70 & .011 & .0125 \\
\hline $\mathbf{A T}_{2} v s . \mathbf{0 O}$ & 19.35 & .000 & .01 \\
\hline
\end{tabular}

Geometric mean \pm SE TOL is shown in Figure 3-2 for every condition and repetition within conditions. Geometric values, or the antilogs of mean \pm SE $\log _{10}$ TOL, are shown in the figure since these better represent central tendencies when the raw data are positively skewed; and, they reflect the mean differences that were actually tested for significance. Most subjects (i.e., 11) occasionally allowed the vehicle's lateral motion to exceed lane boundaries while driving after placebo but the mean percentage of data recorded during these excursions was very low (i.e., $0.26 \%$ ). The overall effects of Alcohol and THC, though not Repetitions, were significant. Mean-pair comparisons showed that the significant main effects were mainly attributable to the drug combinations. Whereas neither alcohol alone nor THC $100 \mu \mathrm{g} / \mathrm{kg}$ alone had appreciable effects, and THC $200 \mu \mathrm{g} / \mathrm{kg}$ alone had an effect that only approached significance $(\mathrm{P}=0.077)$, the two combinations very significantly elevated TOL. Alcohol plus THC $100 \mu \mathrm{g} / \mathrm{kg}$ caused mean TOL to rise above $0.6 \%$, and alcohol plus THC $200 \mu \mathrm{g} / \mathrm{kg}$, to about $1.1 \%$. Nevertheless, the interactive effect of alcohol and THC was not significant. 


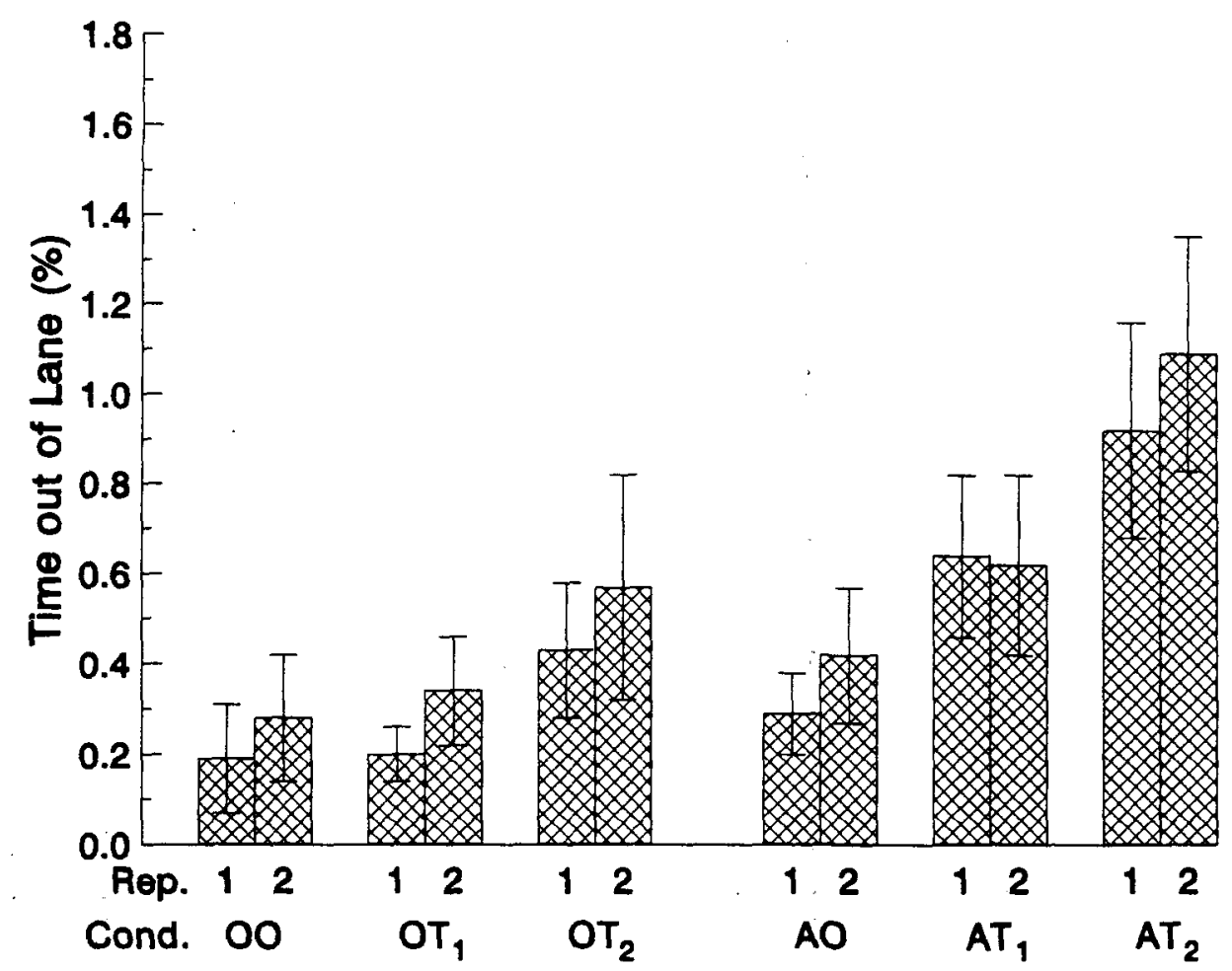

Figure 3-2 Geometric mean ( ${ }^{ \pm} \mathrm{SE}$ ) of Time out of Lane (TOL, \%) in first and second repetitions of the Road Tracking Test in every condition (for definition of treatment conditions, see Table 2-1).

Standard deviation of speed (SDSP) was not significantly affected by any factor. Mean lateral position (MLP) and mean speed (MSP), control variables for ascertaining whether subjects followed their instructions, were similarly unaffected by treatments. Both showed slight effects of Repetitions: on the average, MLP shifted from 8.23 to $10.03 \mathrm{~cm}$ to the right of mid-line $\left(F_{1,17}=5.25 ; P=0.035\right)$ and MSP rose from 97.4 to $97.7 \mathrm{~km} / \mathrm{h}\left(F_{1,17}=3.84\right.$; $\mathrm{P}=0.067)$. More importantly for control purposes, all individuals drove with MLPs between $30 \mathrm{~cm}$ left, and $41 \mathrm{~cm}$ right of mid-line and with MSPs between 91.2 and $101.8 \mathrm{~km} / \mathrm{hr}$. It seems they generally attempted to drive with a steady lateral position near the center of the traffic lane and a constant speed of $100 \mathrm{~km} / \mathrm{h}(62 \mathrm{mph})$. 


\section{Marijuana / Alcohol Driving Study}

\subsection{Car Following}

Table 3-5 summarizes the results of $t$-tests comparing the effects of placebo and every drug treatment on car following parameters averaged separately over acceleration and deceleration maneuvers. No treatment significantly affected any parameter during acceleration maneuvers. Likewise, treatments failed to affect mean headway $\left(\mathrm{H}_{M}\right)$ during deceleration maneuvers. Mean values of $\mathrm{H}_{M}$ varied irregularly between conditions from $41.9 \mathrm{~m}$ in $\mathbf{O T}_{1}$ to $44.2 \mathrm{~m}$ in $\mathbf{O O}$. The lack of any treatment effect on this parameter is important. If drugs caused the subjects to maintain longer average headways, it would be difficult to interpret differences between their effects and placebo's on the other parameters measured in the test. And as indicated in the table, those differences were abundant during deceleration maneuvers.

Table 3-5 Summary of t-test comparisons of drug and placebo effects on average $R T, H_{S D}$ and $H_{M A X} / H_{M \mathbb{N}}$ during acceleration and deceleration maneuvers, separately. Values in the table are mean differences, $t$ and p. Asterisks indicate significant $p$-values according to adjusted $p_{\alpha}$ criteria (for definition of treatment conditions, see Table 2-1).

\begin{tabular}{|c|c|c|c|c|c|c|c|c|c|c|}
\hline \multicolumn{11}{|c|}{ ACCELERATION } \\
\hline & & \multicolumn{3}{|c|}{ RT (sec) } & \multicolumn{3}{|c|}{$\mathbf{H}_{\mathbf{S p}}(\mathbf{m})$} & \multicolumn{3}{|c|}{$\mathbf{H}_{\operatorname{MAX}}(\mathbf{m})$} \\
\hline Comparison & df & $\mathbf{M}_{\mathbf{D}}$ & $t$ & $\mathbf{p}$ & $\mathbf{M}_{\mathrm{D}}$ & $t$ & $\mathbf{p}$ & $\mathbf{M}_{\mathbf{D}}$ & $t$ & $\mathbf{p}$ \\
\hline $\mathrm{OT}_{1} v s .00$ & 16 & 0.17 & 0.36 & ns & 1.70 & 2.36 & .032 & -0.09 & 0.04 & ns \\
\hline $\mathrm{OT}_{2} v s .00$ & 14 & 0.47 & 0.82 & ns & 1.65 & 1.79 & ns & 1.27 & 0.38 & ns \\
\hline AO vs. 00 & 14 & 0.60 & 1.08 & ns & -0.12 & 0.15 & ns & -3.68 & 1.31 & ns \\
\hline $\mathbf{A T}_{1}$ vs. 00 & 15 & 0.16 & 0.29 & ns & 1.01 & 1.19 & ns & -0.43 & 0.16 & ns \\
\hline $\mathbf{A T}_{2}$ vs. $\mathbf{O O}$ & 15 & 0.85 & 2.06 & ns & 1.79 & 2.03 & ns & 0.98 & 0.28 & ns \\
\hline \multicolumn{11}{|c|}{ DECELERATION } \\
\hline & & \multicolumn{3}{|c|}{ RT $(\sec )$} & \multicolumn{3}{|c|}{$\mathbf{H}_{\mathrm{SD}}(\mathbf{m})$} & \multicolumn{3}{|c|}{$\mathbf{H}_{\mathbf{M A X}}(\mathbf{m})$} \\
\hline Comparison & df & $\mathbf{M}_{\mathbf{D}}$ & $t$ & $\mathbf{p}$ & $\mathbf{M}_{\mathbf{D}}$ & $t$ & $\mathbf{p}$ & $\mathbf{M}_{\mathbf{D}}$ & $t$ & p \\
\hline $\mathrm{OT}_{1} v s .00$ & 16 & 0.92 & 1.75 & ns & 1.25 & 2.85 & $.012^{*}$ & -4.89 & 4.14 & $.001^{*}$ \\
\hline $\mathrm{OT}_{2} v s .00$ & 14 & 1.29 & 1.95 & ns & 1.96 & 3.76 & $.002^{*}$ & -2.81 & 1.71 & ns \\
\hline $\mathbf{A O}$ vs. 00 & 14 & 0.51 & 1.07 & ns & 0.89 & 2.31 & $.036^{*}$ & -4.07 & 2.91 & $.011^{*}$ \\
\hline $\mathbf{A T}_{1} v s .00$ & 15 & 1.15 & 1.88 & ns & 1.86 & 2.51 & $.025^{*}$ & -4.17 & 3.21 & $.006^{*}$ \\
\hline $\mathbf{A T}_{2}$ vs. $\mathbf{O O}$ & 15 & 1.57 & 3.02 & $.009 *$ & 2.17 & 3.97 & $.001^{*}$ & -3.41 & 3.07 & $.008^{*}$ \\
\hline
\end{tabular}

Figure 3-3 shows mean \pm SE for RT, $\mathrm{H}_{\mathrm{SD}}$ and $\mathrm{H}_{\mathrm{MN}}$ in every condition. Mean RT rose from the placebo level after every drug treatment. The mean difference for $\mathbf{A T}_{\mathbf{2}}$ was significant, and for $\mathbf{O T}_{1}, \mathbf{O T}_{2}$ and $\mathbf{A T} \mathbf{T}_{1}$, nearly so $(\mathrm{P} \leq 0.10)$. All of the mean differences in $\mathrm{H}_{S D}$ were significant after $\mathrm{p}_{\alpha}$ adjustment for multiple comparisons. So were differences in $\mathrm{H}_{\mathrm{MNN}}$, except that between $\mathbf{O O}$ and $\mathbf{O T}_{2}$. Thus, in one, two or all three respects, every drug treatment impaired car following performance relative to placebo. 


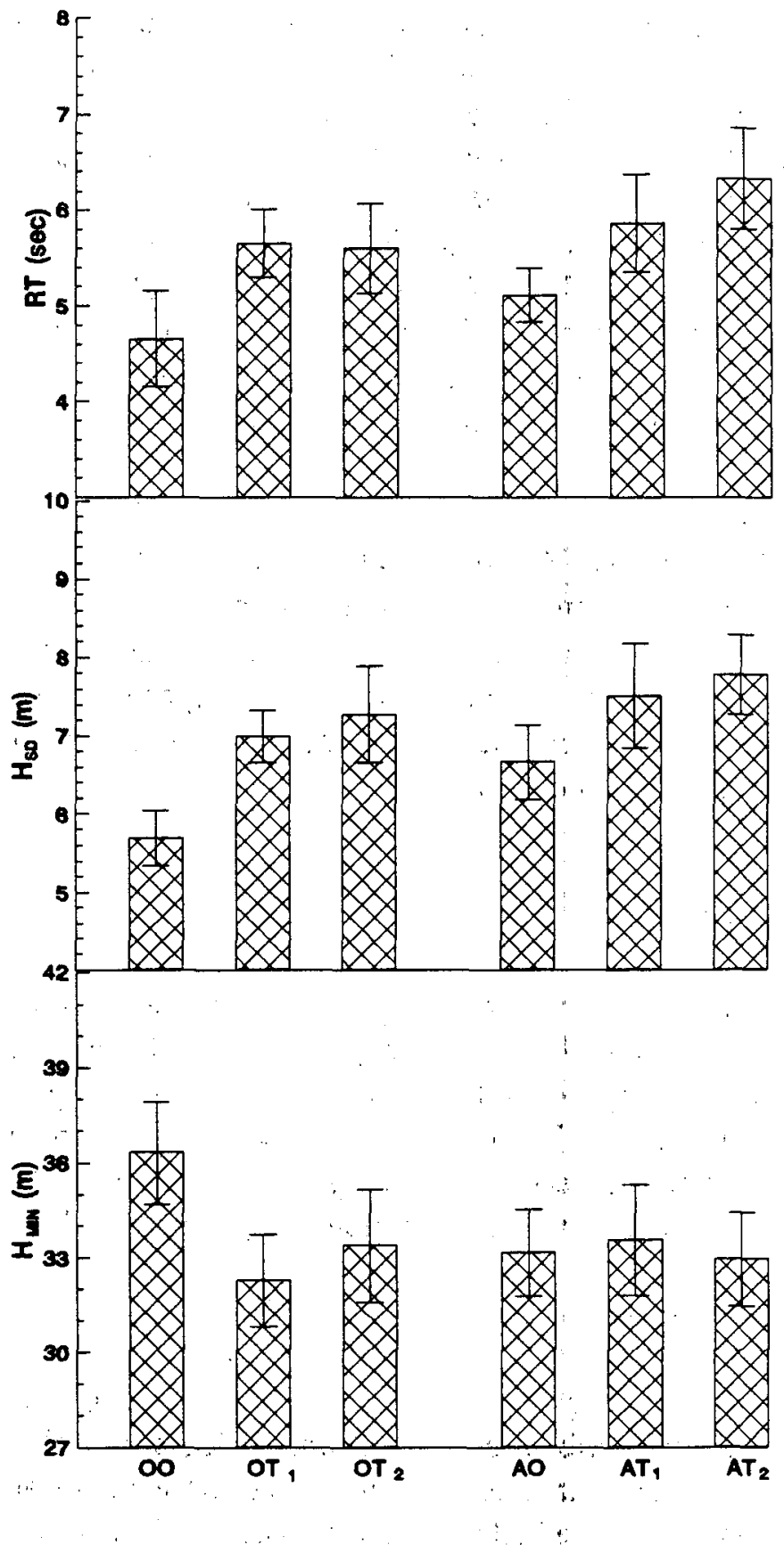

Figure 3-3 Mean ( \pm SE) Reaction Time $(\mathrm{RT}, \mathrm{sec})$, Standard Deviation of Headway $\left(\mathrm{H}_{\mathrm{SD}}, \mathrm{m}\right)$, and Minimum Headway $\left(\mathrm{H}_{\mathrm{MaN}}, \mathrm{m}\right)$ during deceleration maneuvers in the Car Following Test in every condition (for definition of treatment conditions, see Table 2-1). 


\section{Marijuana / Alcohol Driving Study}

\subsection{Intoxication Ratings}

Subjects began the various conditions making estimates of their degrees of intoxication that were reasonable considering the treatments given beforehand. Some at the beginning of the double placebo condition thought they felt something and reported low levels of intoxication (mean \pm SD, $7.67 \pm 2.37 \%$ ). However, nearly all reported stronger feelings after alcohol and both THC doses, given alone; i.e., $44.56 \pm 5.48,29.11 \pm 4.20$ and $36.50 \pm 7.10 \%$, respectively. Combinations of alcohol with low and high THC doses produced still higher intoxication ratings; i.e., $52.89 \pm 4.66$ and $62.87 \pm 4.90 \%$, respectively. No subject felt normal after alcohol alone or either combination of Alcohol and THC. Both of the latter produced extreme ratings above $90 \%$. In all conditions, mean intoxication ratings at the conclusion of testing were at levels about half of where they began. As might be expected, both the overall effects of alcohol and THC were highly significant $\left(F_{1,17} \& 2,16=76.04,19.76 ; P \leq 0.001\right)$. The linear THC dose effect was also significant $\left(F_{1,17}=41,97 ; P \leq 0.001\right)$. There was a significant Alcohol $x$ THC interaction $\left(F_{2,16}=10.07 ; P \leq 0.001\right)$. However, this finding is mitigated by the failure to find a significant linear component of that interaction $\left(\mathrm{F}_{1,17}=0.78\right)$. Instead, the quadratic component was significant $\left(\mathrm{F}_{1,17}=11.52 ; \mathrm{P} \leq 0.003\right)$. One can not interpret this interaction as showing that the rise in feelings of intoxication was steeper over THC doses given with alcohol. Rather it reflected the fact that the rise was precipitous from $\mathbf{O O}$ to $\mathbf{O T}_{1}$ and $\mathbf{O T}_{2}$ but more gradual from $\mathbf{A O}$ to $\mathbf{A} \mathbf{T}_{1}$ and $\mathbf{A} \mathbf{T}_{2}$.

\subsection{Driving Quality Ratings}

Subjects rated their driving quality at the end of every test repetition. Instructors rated the subjects' performance in parallel. A summary of results from analyses comparing the subjects' and instructors' ratings over treatment conditions and repetitions of tests within conditions is given in Table 3-6. Mean \pm SE ratings by both are shown in Figure 3-4. Also given are the frequencies of scores indicating that the subjects' driving quality was unacceptable; i.e., that in their own or the instructor's opinion, they had "failed" the test.

Instructors rated the subjects' performance as significantly worse than the subjects did themselves. The mean differences were not large in magnitude and otherwise the two sets of ratings were quite similar. Ratings of the subjects' performance in the Road Tracking Test clearly reflected the separate effects of alcohol and THC; and, THC's linear dose effect. Somewhat surprisingly, those ratings did not show a separate significant effect of alcohol in the Car Following Test. THC's effects and its increase with dosage were, however, also apparent in this context. Both subjects and instructors rated the subjects' performance as generally worse in the first repetitions of both tests. The ratings showed a significant Alcohol 
by THC interaction. But as with the interaction involving the intoxication ratings (above), the quadratic but not the linear component was significant. Thus the interaction for driving quality ratings must be interpreted in the same manner.

Table 3-6 Summary of MANOVA/ANOVA for Subjects and Instructor Ratings of Driving Quality in Road Tracking and Car Following Tests.

\begin{tabular}{llllll}
\hline EFFECT & \multicolumn{3}{l}{ ROAD TRACKING } & \multicolumn{2}{l}{ CAR FOLLOWING } \\
\hline & df & F & p & F & p \\
\cline { 2 - 7 } Rater (P) & 1,17 & 16.95 & .001 & 7.26 & .015 \\
Alcohol (A) & 1,17 & 4.67 & .045 & 1.23 & ns \\
THC: overall & 2,16 & 13.62 & .000 & 7.61 & .005 \\
Linear over doses & 1,17 & 24.79 & .000 & 16.16 & .001 \\
Quadratic over doses & 1,17 & 0.48 & ns & 0.05 & ns \\
Repetitions & 1,17 & 23.41 & .000 & 14.47 & .001 \\
P x A & 1,17 & 1.00 & ns & 0.05 & ns \\
P x THC: overall & 2,16 & 0.17 & ns & 0.89 & ns \\
Linear over doses & 1,17 & 0.27 & ns & 0.81 & ns \\
Quadratic over doses & 1,17 & 0.06 & ns & 1.41 & ns \\
P X R & 1,17 & 3.17 & ns & 1.43 & ns \\
A X THC: overall & 2,16 & 7.90 & .004 & 5.04 & .020 \\
Linear over doses & 1,17 & 0.06 & ns & 1.21 & ns \\
Quadratic over doses & 1,17 & 13.39 & .002 & 10.54 & .005 \\
A x R & 1,17 & 0.05 & ns & 0.17 & ns \\
THC X R: overall & 2,16 & 1.58 & ns & 0.00 & ns \\
Linear over doses & 1,17 & 0.04 & ns & 0.01 & ns \\
Quadratic over doses & 1,17 & 3.31 & ns & 0.00 & ns \\
\hline
\end{tabular}

[2nd-order interactions and higher are omitted. None was significant]

"Failures" occurred more frequently in the instructors' ratings than the subjects'; and, with about equal frequencies in both driving tests. According to the instructors, about half of the subjects' driving was so poor that they failed in $\mathbf{A} \mathbf{T}_{2}$ and about one-third in $\mathbf{A} \mathbf{T}_{1}$. The failure rate was lower and about the same in $\mathbf{O T}_{2}$ and $\mathbf{O T} \mathbf{T}_{1}$. 


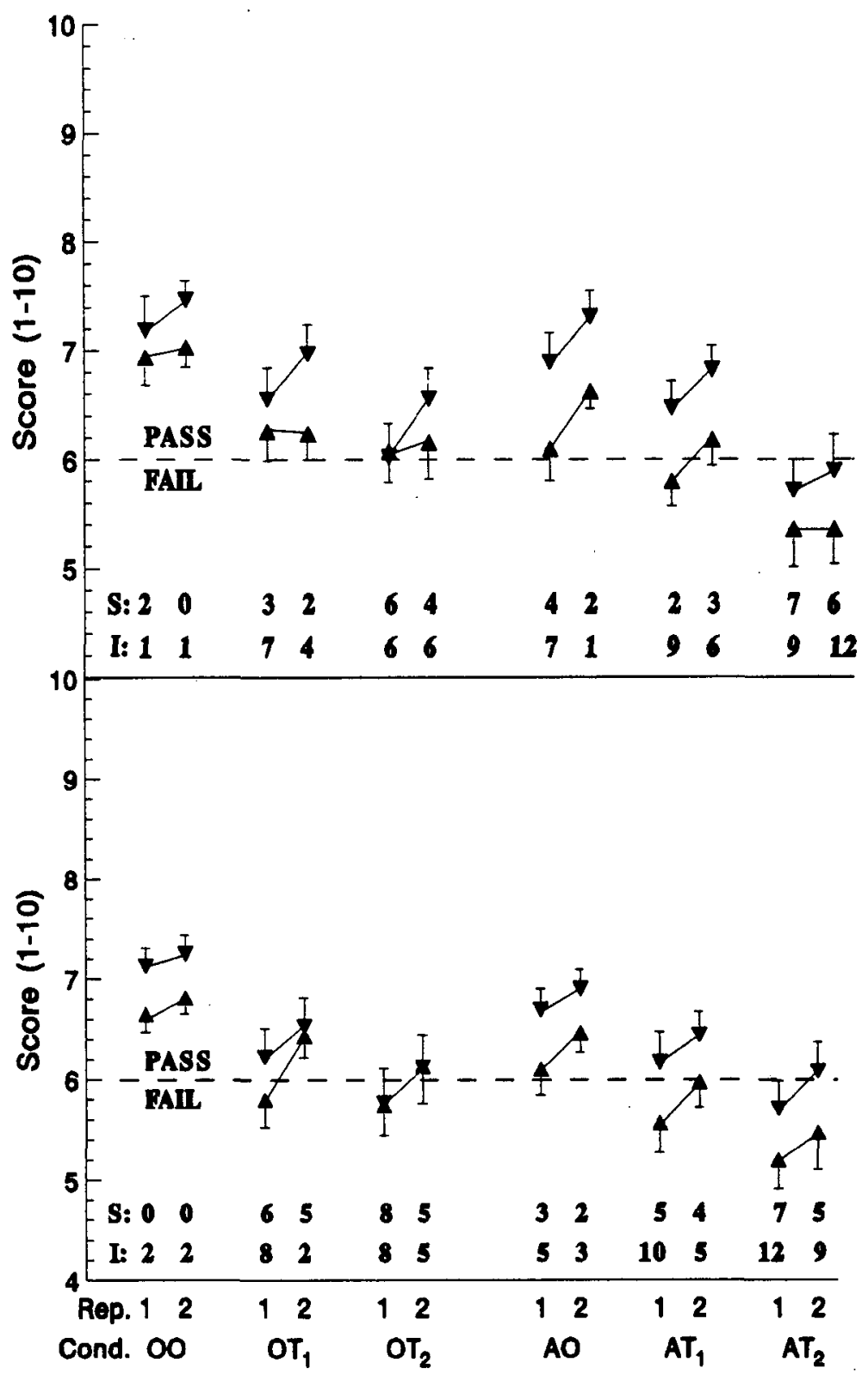

Figure 3-4 Mean (+SE) ratings of driving performance in the Road Tracking (top) and Car Following Test (bottom), in each treatment condition, as scored by the driving instnuctors $(\mathbf{A})$ and the subjects $(\nabla)$. Also shown are the frequencies of subjects failing the particular testrepetition according to themselves (S) and the instructors (I) (for definition of treatment conditions, see Table 2-1). 


\section{Marijuana / Alcohol Driving Study}

\subsection{Instructor's Comments}

Table 3-7 summarizes the instructor's written comments concerning particularly unusual or extreme aspects of the subjects' driving behavior in the various treatment conditions. Only one (\#11) drew any comment in the double placebo condition. At the other extreme, 10 subjects drew comments after being treated with the combination of alcohol and THC $200 \mu \mathrm{g} / \mathrm{kg}$. Only three, all females (\#10,\#13,\#16), failed to elicit any comment.

Table 3-7 Summary of Instructor's Comments concerning unusually deviant driving behavior by subjects within conditions. Males identified as subjects 01-09, females, as 10-18 (for definition of treatment conditions, see Table 2-1).

\begin{tabular}{|c|c|c|c|c|c|c|}
\hline & \multicolumn{6}{|c|}{ CONDITIONS } \\
\hline COMMENTS & 00 & $\mathbf{O T}_{1}$ & $\mathbf{O T}_{2}$ & AO & $\mathbf{A T _ { 1 }}$ & $\mathbf{A} \mathbf{T}_{2}$ \\
\hline Very drowsy \& inattentive & 11 & 11,14 & $5,7,11$ & 1 & 11,17 & $1,3,11$ \\
\hline Drifting \& weaving & 11 & 11 & 7,11 & 3,4 & 11,15 & $3,5,11,14,17$ \\
\hline Swerving \& overcorrecting & & 5,15 & & & & $1,11,14,17$ \\
\hline Speed too fast & & & & & 11 & 17 \\
\hline Speed too slow & & & & & 18 & \\
\hline Speed too variable & & & 11 & & 11,17 & 17 \\
\hline Car following: too close & & 11,15 & & & $11,15,17,18$ & $8,11,12$ \\
\hline Car following: too far & & & 3 & 2 & $9,11,17,18$ & 8,14 \\
\hline Reckless & & & & & & 17 \\
\hline Memory loss & & & & & 11 & $4,6,14$ \\
\hline Attempted dangerous passing & & 11 & 14 & & 11 & 11 \\
\hline \# events & 2 & 8 & 8 & 4 & 18 & 24 \\
\hline \# subjects & 1 & 4 & 5 & 4 & 5 & 10 \\
\hline
\end{tabular}

The data presented in the table are self explanatory, except those in the last three categories. One subject's (\#17) behavior was described as reckless in $\mathbf{A T}_{\mathbf{2}}$ because she drove at speeds well above $100 \mathrm{~km} / \mathrm{h}(62 \mathrm{mph})$ while weaving, swerving and abruptly overcorrecting. When repeatedly cautioned by the instructor to maintain the designated speed, she immediately did so but shortly resumed driving as before. Four subjects apparently experienced bizarre memory disturbances, one (\#11) in $\mathbf{A T}_{1}$ and the others (\#04, \#06, \#14) in $\mathbf{A T}_{2}$. Subject \#11's disturbance occurred in the Road Tracking Test. She began driving after the departure of the other subject who was performing the Car Following Test. She eventually overtook and proceeded to pass that subject's vehicle on the left, but failed to recognize it or the leading vehicle under an investigator's control. She completed the maneuver by returning to the right traffic lane between the vehicles engaged in this test. She was visibly surprised when the instructor drew the error to her attention. Subjects' \#04 and \#06 memory lapses were similar: midway through the Car Following Test, both forgot the procedure and attempted to pass the leading vehicle. Another (\#14) correctly followed the procedure 
during the same test but upon its conclusion, failed to leave the highway with the leading vehicle at the designated exit. She apparently would have continued to drive on the highway beyond that point if not corrected by the instructor. Finally, subject \#11 in $\mathbf{O T}_{1}, \mathbf{A T}_{1}$ and $\mathbf{A T}_{2}$, and subject \#14 in $\mathbf{O T}_{2}$, had to be prevented from beginning a passing maneuver while their vehicle was in the process of being overtaken by other traffic. It seemed to the instructor that the subjects failed to inspect the rear-view mirrors before initiating these maneuvers. 
Marijuana / Alcohol Driving Study

\section{DISCUSSION}

Four studies preceded the present one in this series (Robbe \& O'Hanlon, 1993). The first and third are relevant to this discussion. The former involved 23 experienced THC users who were allowed to continuously smoke marijuana cigarettes (THC, $2.57 \%$ ) in a clinical environment until arriving at their desired "high." The preferred mean dose was close to $300 \mu \mathrm{g} / \mathrm{kg}$. A different group of 15 similarly experienced users completed the third study. On separate occasions, they smoked marijuana-placebo and marijuana delivering THC 100, 200 and $300 \mu \mathrm{g} / \mathrm{kg}$. The drug's effects on driving were assessed 55-170 min. post-dosing in essentially the same manner as during the present study. No dose significantly affected this group's car following performance but all elevated SDLP in the Road Tracking Test. Relative to the placebo level, mean SDLP rose by $1.1,1.8$ and $2.9 \mathrm{~cm}$ in rough proportion to the THC dose. Though all significant, these changes were very modest in comparison to those produced by alcohol and a number of medicinal drugs in previous investigations. Alcohol was used as the agent for calibrating the standard test (Louwerens et al, 1987). Social drinkers performed it on five separate occasions while their BACs were controlled in equal steps between 0.00 and $0.15 \mathrm{~g} / \mathrm{dl}$. The drinkers' mean SDLP rose exponentially with BAC $(R=0.99)$ and an empirical equation was derived for describing the relationship. The equation has been subsequently used for describing drugs' effects on SDLP in terms of respective BAC equivalencies. When we applied it for describing THC's effects in the earlier study, the maximum mean change after $300 \mu \mathrm{g} / \mathrm{kg}$ was found to be the equivalent of BAC $=0.08 \mathrm{~g} / \mathrm{dl}$. THC's effects were also far less than those of some commonly used medicinal drugs. For example, after a week of receiving diazepam $5 \mathrm{mg}$ (Valium ${ }^{8}$ ), thrice daily, and lorazepam $2 \mathrm{mg}$ (Ativan), twice daily, different groups of clinically anxious patients drove with mean SDLPs that were respectively 7 and $10 \mathrm{~cm}$ higher than baseline (Van Laar et al, 1992; O'Hanlon et al, 1995). Thus, we concluded that THC taken alone in doses preferred by its users does not seriously affect driving performance.

We originally intended to administer the same THC doses, alone and in combination with alcohol, in the present study. However, the results of a pilot study deterred us from using the $300 \mu \mathrm{g} / \mathrm{kg}$ dose. In combination with the specified alcohol dose, it rendered some subjects incapable of standing much less driving. We therefore proceeded to administer only the two lower doses, believing that these would be sufficient for determining the nature of THC's interaction with alcohol.

Subjects who participated in this study differed in several important respects from the predecessors. They were younger than the groups who defined the preferred dose and completed the earlier driving study (22.7 years in the present versus 25.7 and 26.8 in the previous studies); they had fewer years of driving experience (4.3 years versus 6.7 and 5.9 


\section{Marijuana / Alcohol Driving Study}

years); and, most importantly, their marijuana smoking frequency was less than half of either preceding group's (2.3 versus 5.8 and 5.4 times per month). These differences should be borne in mind while comparing the studies' results. One may reasonably assume that the older, more frequent THC users had driven more often under the drug's influence, and there is little doubt that the frequent use of any impairing drug fosters "behavioral tolerance" or state-related and task-specific learning to compensate for its influence on performance (review: Young and Goudie, 1994). Behavioral tolerance is unlike pharmacological tolerance that either lowers a drug's circulating concentration or diminishes its activity at receptor sites when taken continually in the same doses over days or weeks. Rather, behavioral tolerance develops as the user practices the task while intoxicated on occasions that can be widely separated in time. Given the present group's youth, limited driving experience and low rate of THC use, it seems unlikely that many could have developed the behavioral tolerance of the predecessors. Which group is more representative of THC users in general is an open question. Probably neither is truly representative, both were drawn from different bands in a very broad spectrum. If there is any distinction to be made, it is that the present group comprised a sample of relatively inexperienced THC users who might be especially vulnerable to the drug's impairing effects on driving.

These subjects' performance in the Road Tracking Test clearly showed the adverse effects of alcohol and THC. Alcohol alone caused mean SDLP to rise by $2.2 \mathrm{~cm}$ over the placebo level. That change was almost exactly as predicted from Louwerens et al's equation for drivers operating with $\mathrm{BAC}=0.05 \mathrm{~g} / \mathrm{dl}$. Thus the present group demonstrated their normal sensitivity to this impairing effect of alcohol on driving. Separate doses of 100 and $200 \mu \mathrm{g} / \mathrm{kg}$ caused mean SDLP to rise by 2.7 and $3.5 \mathrm{~cm}$, respectively. These changes were well above those shown after the same doses by the earlier group. Yet despite the absolute differences, the increments in both groups' mean SDLPs as their doses increased from 100 to $200 \mu \mathrm{g} / \mathrm{kg}$ were practically the same; i.e., 0.8 and $0.7 \mathrm{~cm}$, respectively. This suggests that while the minimum dose for affecting the present group's driving performance was lower, their dose-response was almost identical to the previous group's whose greater resistance to THC's effect on driving performance could be the consequence of behavioral or pharmacological tolerance, or both.

The effects of combined alcohol and THC on the present subjects' road tracking performance were severe. Alcohol plus THC 100 and $200 \mu \mathrm{g} / \mathrm{kg}$ respectively elevated mean SDLP by 5.3 and $8.5 \mathrm{~cm}$. The former change was comparable to that predicted from Louwerens et al's equation for driving with $\mathrm{BAC}=0.09 \mathrm{~g} / \mathrm{dl}$. The latter change was equivalent to driving with $\mathrm{BAC}=0.14 \mathrm{~g} / \mathrm{dl}$. It has only been exceeded in all studies employing the standard test by that occurring after lorazepam $2 \mathrm{mg}$ (see above). Judging from SDLP, 
the subjects' performance deteriorated more after both combinations than it would have if they simply had driven after consuming enough alcohol to become legally intoxicated.

The subjects' progressive loss of control over the vehicle's lateral position as the drugs' effects went from bad to worse first led to rising SDLP, and later, TOL. The relationship between mean SDLP and TOL across both test repetitions in every condition is shown in Figure 4-1. The function describing that relationship was derived from least-squares regression analysis following an exponential model: TOL $=0.00359 \mathrm{e}^{0.18491(\mathrm{SDLP})}$. The model was selected on the basis of a mathematical argument by Allen and O'Hanlon (1979). Those authors showed that TOL must necessarily increase as an exponential function of SDLP so long as drivers generally operate with a Gaussian distribution of lateral position around a stable mean. In any case, the empirical equation adequately describes the data $\left(R^{2}=0.89\right)$. It implies that the subjects' SDLPs could not have risen much further without a totally unacceptable increase in TOL. As it was, while mean SDLP increased from the lowest to the highest values in this study by $43 \%$, mean TOL rose by $474 \%$.

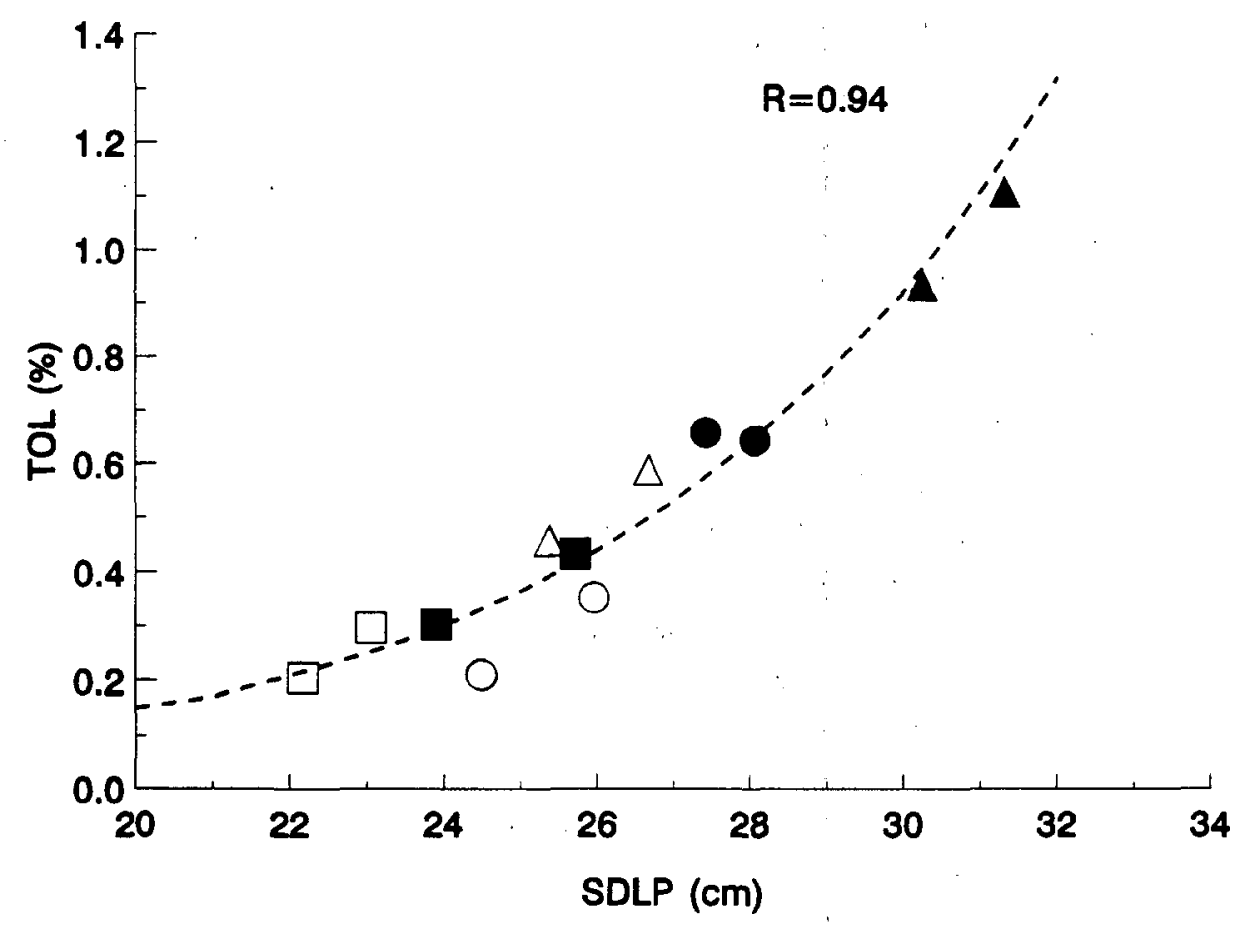

Figure 4-1 Geometric mean TOL as a function of mean SDLP across conditions: 00 ( ), $\mathbf{O T}_{1}(\mathrm{O}), \mathbf{O T}_{2}(\Delta), \mathbf{A O}(\varpi), \mathbf{A T}_{1}(\bullet), \mathbf{A T}_{2}(\Delta)$. (For definition of treatment conditions, see Table 2-1.) 


\section{Marijuana / Alcohol Driving Study}

The exponential rise in TOL from conditions where alcohol and THC were separately administered to those where they were given in combination suggests a synergistic interaction. However, the statistical test failed to show a significant interaction between alcohol and THC effects on TOL. But TOL was little affected by any treatment other than the combinations. By taking the data from all conditions together into a single analysis, $2 / 3$ of them mainly contributed error variance. Regardless of the additivity or multiplicity of the drugs' effects, there can be no doubt that their combination is potentially very dangerous for driving. Neither drug's doses in this study were particularly high and one may reasonably suppose that drivers in the real world occasionally operate after consuming more of one or both in combination. If they do, our results suggest that their increasingly large and frequent excursions from the relative safety of a traffic lane would occupy a considerably greater percentage of the distance traveled. This alone would increase the driver's risk of losing control as the vehicle leaves the paved surface of the road, of striking a fixed object at roadside or of swerving into the path of an approaching or overtaking vehicle. The risks of all types of collisions could rise in parallel if, as is thought, the loss of lateral position control is but one sign of general driving impairment.

An indication that the drugs' adverse influence on driving performance was pervasive came from the Car Following Test. Despite missing data which necessitated an unparsimonious and relatively weak analysis, its results supported those from the other driving test. Changes in mean $\mathrm{RT}$ and $\mathrm{H}_{\mathrm{SD}}$ roughly paralleled those in mean SDLP. Performance after placebo was always the best, and after the combination of alcohol and THC $200 \mu \mathrm{g} / \mathrm{kg}$, always the worst. THC dose effects, with and without alcohol were apparent for all performance measures. Mean RT did not differ significantly after drug and placebo treatments, except in the worst case. Yet those differences were large in practical terms. The difference due to the combined effect of alcohol and THC $200 \mu \mathrm{g} / \mathrm{kg}$ was $1.6 \mathrm{sec}$. Since the average speed in that condition was about $97 \mathrm{~km} / \mathrm{h}(59 \mathrm{mph})$, this delay meant that the vehicle traveled, on the average, an additional $42 \mathrm{~m}(139 \mathrm{ft})$ beyond the point where the subjects began to decelerate after placebo treatment. Even the lowest THC dose, by itself, retarded the subjects' mean RT by $0.9 \mathrm{sec}$. In that case, they "only" drove an additional $24 \mathrm{~m}(78 \mathrm{ft})$ before beginning to decelerate. It does not take much effort to imagine how response delays between 0.9 and $1.6 \mathrm{sec}$ could affect safety in real car following.

The drugs' effect on mean $\mathrm{H}_{\mathrm{SD}}$ was clearer: that parameter was significantly affected by every drug treatment. The changes in mean $\mathrm{H}_{\mathrm{SD}}$ reveal another adverse drug effect on driving; i.e., diminished ability to perceive changes in the relative velocities of other vehicles and/or diminished ability to adjust one's own vehicle's speed accordingly. They also indicate a subtle hazard the drug user might pose for other drivers operating in traffic platoons during high speed travel on highways. The changes from $\mathbf{O O}$ to $\mathbf{A T}_{2}$ in this study were about 2-m during both acceleration and deceleration maneuvers. Assuming a Gaussian 


\section{Marijuana / Alcohol Driving Study}

distribution of headway variance, this means that the subjects' total range of to and fro oscillation increased by about $12 \mathrm{~m}$ (i.e., $6 \times \Delta \mathrm{H}_{\mathrm{SD}}$ ) or $39 \mathrm{ft}$ under the combined influence of alcohol and THC $200 \mu \mathrm{g} / \mathrm{kg}$. In real life, that abnormal headway variability would be transmitted to and amplified by every driver/vehicle in retrograde succession (i.e., the "accordion effect"). Unless succeeding drivers compensated by opening the gaps between vehicles, one in the series would find it impossible to react quickly enough to avoid a collision.

Despite the observed impairments, the subjects seemed well aware of their impairment in both tests. Their self-ratings of driving quality varied over conditions in general agreement with the objective measurements. The instructors rated their driving quality as even lower but the differences in these assessments were not large. Some subjects, particularly after THC $200 \mu \mathrm{g} / \mathrm{kg}$ alone or in combination with alcohol, indicated that they had failed the tests. Why they continued to drive in these conditions is a good question. They probably would not have proceeded, nor undertaken the tests in the first place, were it not for their reliance on the instructors to prevent untoward consequences. Though reliance on the instructor was definitely not encouraged, it may be an inevitable artifact of this experimental approach. A further indication that participation in an experiment encouraged the subjects to drive when they ordinarily would not may be taken from their previous histories. Whereas all subjects admitted previously driving under the influence of THC, only three men said they had done so after using alcohol and THC in combination.

Finally, something should be mentioned about the observers' comments. Though unsystematic and probably biased by general knowledge of the subjects' treatments, these supported the objective results and also revealed some idiosyncratic reactions that would have otherwise gone undetected. In general, the subjects remained responsive to the instructors' occasional corrections. Only one woman drove in a manner they considered "reckless", and even she followed their instructions, if only briefly. Poor attention to the driving task and deficient control over the vehicle's speed and lateral position were the most frequently observed signs of the subjects' impairment. Memory disturbances afflicting four subjects after combined drug treatments were the most dramatic. They suddenly failed to recall what should have been very familiar test procedures. Many drugs, such as alcohol and the benzodiazepines, interfere with the acquisition and/or later recall of information while the drug is active in the brain. None of them is known to consistently prevent the recall of well practiced procedures. That THC occasionally did so in this, our earlier studies, and one other study (Yesavage, 1985), suggests that the drug may possess unique amnestic properties. The phenomenon is worthy of further investigation. 


\section{Marijuana / Alcohol Driving Study}

\section{CONCLUSIONS}

\subsection{General Conclusions}

In a previous series of studies on the effects of THC alone we concluded that THC given in doses up to $300 \mu \mathrm{g} / \mathrm{kg}$ has "slight" effects on driving performance (Robbe \& O'Hanlon, 1993). The results of the present study now compel us to revise that conclusion. The present subjects' performance was more affected than their predecessors'. The present subjects showed impaired car following performance after THC $100 \mu \mathrm{g} / \mathrm{kg}$ whereas the previous ones were not impaired by doses up to $300 \mu \mathrm{g} / \mathrm{kg}$. In the present study, road tracking performance after $200 \mu \mathrm{g} / \mathrm{kg}$ was worse than the performance after $300 \mu \mathrm{g} / \mathrm{kg}$ in the previous study. We believe that these differences are attributable to the groups' respective experience with THC smoking and to driving under the influence of THC. The present group was less experienced and probably had not developed the same degree of behavioral tolerance as their predecessors. Yet all of the individuals in both groups admitted to having occasionally driven under the influence of THC before entering the studies. Thus, the new data seem no less representative of how drivers normally operate under the influence of THC. The addition of these data to those previously collected merely broadens the range of reactions that might be expected to occur in real life. That range has not been shown to extend into the area that can rightfully be regarded as dangerous or an obviously unacceptable threat to public safety. Alcohol present in blood concentrations around the legal limit $(0.10 \mathrm{~g} / \mathrm{dl})$ in most American States is more impairing than anything subjects have shown after THC alone in our studies. As mentioned, medicinal drugs have had worse effects on psychiatric patients' driving performance in other studies employing the same test procedures. If not blatantly dangerous, however, the effects of THC alone in this study were certainly more than slight. They were of sufficient magnitude to warrant concern. Drivers suffering the same degrees of impairment as the present subjects did after THC alone would be less than normally able to avoid collisions if confronted with the sudden need for evasive action. They would probably also be more likely to fall asleep during prolonged vehicle operation. In short, while the effects of THC alone in doses up to $200 \mu \mathrm{g} / \mathrm{kg}$ might be categorized as "moderate" in the tests, they could easily become "severe" under exceptional circumstances.

The subjects' reactions to combined use of alcohol and THC are another matter. Drivers suffering the same degrees of impairment as the present subjects did after THC and alcohol, combined, would be exceedingly dangerous. Their impairment would be a serious threat to their own safety, and perhaps to the general driving public as well. The simultaneous consumption of low to moderate doses of alcohol and THC, rendered the present subjects incapable of safe driving for several hours thereafter. That they were able to safely 


\section{Marijuana / Alcohol Driving Study}

demonstrate their impairment was, on occasion, only possible because of the instructor's intervention. Had these individuals attempted to drive alone in that condition, it is quite possible that one or more would have caused a collision.

\subsection{Specific Conclusions}

- THC alone in $100-200 \mu \mathrm{g} / \mathrm{kg}$ doses impairs fundamental road tracking ability with the degree of impairment increasing as a function of the dose.

- The impairment from THC alone does not diminish and may even increase for up to $2 \frac{1 / 2}{2}$ hours after marijuana smoking, regardless of the THC dose.

- THC in $100-200 \mu \mathrm{g} / \mathrm{kg}$ doses, in combination with alcohol sufficient for producing $\mathrm{BAC} \approx 0.04 \mathrm{~g} / \mathrm{dl}$, severely impairs road tracking ability with the degree of impairment again increasing with the THC dose.

- THC and alcohol effects on road tracking ability appear to be additive in a pharmacological sense, but the risk of driving off the road increases exponentially with the combined drug effect.

- THC alone in $100-200 \mu \mathrm{g} / \mathrm{kg}$ doses can impair the ability to maintain a constant headway while attempting to match velocity with a preceding vehicle.

- THC $200 \mu \mathrm{g} / \mathrm{kg}$ in combination with alcohol seriously retards reaction time to the deceleration of a preceding vehicle.

- The effects of THC and alcohol on headway maintenance and reaction time also appear to be additive but the sum in both cases can be large and potentially dangerous. 
Marijuana / Alcohol Driving Study

\section{REFERENCES}

Allen RW, O'Hanlon JF (1979). Driver steering performance effects of roadway delineation and visibility conditions. Proceedings of Transportation Research Board Annual Meeting. (Washington DC) Paper No. 229.

Attwood DA, Williams RD, Bowser JS, McBurney LJ, Frecker RC (1981). The Effects of Moderate Levels of Alcohol and Marijuana, Alone and in Combination on ClosedCourse Driving Performance. Tech Rep 81-RSU-17, Defense and Civil Institute of Environmental Medicine, Downsview, Ontario.

Brookhuis KA, Volkerts ER, O'Hanlon JF (1987). The Effects of some anxiolytics on carfollowing performance in real traffic. In: PC Noordzij, R Roszback (Eds.), Alcohol, Drugs and Traffic Safety - T86, Excerpta Medica, Amsterdam, 223-226.

Budd RD, Muto JJ, Wong JK (1989). Drugs of abuse found in fatally injured drivers in Los Angeles County. Drug and Alcohol Dependence, 23, 153-158.

Casswell S (1979). Cannabis and Alcohol: Effects on closed-course driving behavior. In: I Johnson (Ed.) Seventh International Conference on Alcohol, Drugs and Traffic Safety. Australian Government Publishing Service, Canberra, 23-28.

Chesher GB (1986). The effects of alcohol and marijuana in combination: A review. Alcohol, Drugs and Driving, 2, 105-120.

Cimbura G, Warren RA, Bennett RC, Lucas DM, Simpson HM (1980). Drugs detected in fatally injured drivers and pedestrians in the Province of Ontario. Traffic Injury Research Foundation of Canada, Ottawa.

Cimbura G, Lucas DM, Bennett RC, Warren RA, Simpson HM (1982). Incidence and toxicological aspects of drugs detected in 484 fatally injured drivers and pedestrians in Ontario. Journal of Forensic Sciences, 27, 855-867.

Daldrup T, Reudenbach G, Kimm K (1987). Cannabis und Alkohol im Strassenverkehr. Blutalkohol, 24, 144-156.

Donelson AC, Cimbura G, Bennett RC, Lucas DM (1985). The Ontario monitoring project: Cannabis and alcohol use among drivers and pedestrians fatally injured in motor vehicle accidents from March 1982 through July 1984. Traffic Injury Research foundation of Canada, Ottawa.

Garriott JC, Di Maio VJM, Rodriguez RG (1986). Detection of cannabinoids in homicide victims and motor vehicle fatalities. Journal of Forensic Sciences, 31, 1274-1282.

Louwerens JW, Gloerich ABM, De Vries G, Brookhuis KA, O'Hanlon JF (1987). The relationship between drivers, blood alcohol concentration (BAC) and actual driving performance during high speed travel. In: PC Noordzij, R Roszbach (Eds.) Alcohol, Drugs and Traffic Safety - T86, Excerpta Medica, Amsterdam, 183-192. 


\section{Marijuana / Alcohol Driving Study}

McLean S, Parsons RS, Chesterman RB, Dineen R, Johnson MG, Davies NW (1987). Drugs, alcohol and road accidents in Tasmania. The Medical Journal of Australia, 147, 6-11.

O'Hanlon JF (1984). Driving performance under the influence of drugs: Rationale for, and application of, a new test. British Journal of Clinical Pharmacology, 18, 121S-129S.

O'Hanlon JF, Ramaekers JG (1995). Antihistamines and actual driving performance in a standard test: A summary of Dutch experience, 1987-1994. Allergy, 50, 234-242.

O'Hanlon JF, Vermeeren A, Uiterwijk MMC, van Veggel LMA, Swijgman HF (1995). Anxiolytics' effects on the actual driving performance of patients and healthy volunteers in a standardized test: An integration of three studies. Neuropsychobiology, 31, 81-88.

O'Hanlon JF, Brookhuis KA, Louwerens JW, Volkerts ER (1986). Performance testing as part of drug registration. In: JF O'Hanlon, JJ de Gier (Eds.). Drugs and Driving, Taylor \& Francis: London, 311-330.

Overall JE, Rhoades HM (1985). Adjusting $\mathrm{p}$ values for multiple tests of significance. In: HY Meltzer (Ed.) Psychopharmacology: The Third Generation of Progress, Raven Press, New York, 1013-1018.

Peck RC, Biasotti A, Borland PN, Mallory C, Reeve V (1989). The effects of marijuana and alcohol on actual driving performance. Alcohol, Drugs and Driving, 2, 135-154.

Ramaekers JG, O'Hanlon JF (1994). Acrivastine, terfenadine and diphenhydramine effects on several aspects of driving performance as a function of dose and time after dosing. European Journal of Clinical Pharmacology, 47, 261-266.

Robbe HWJ (1994). Influence of Marijuana on Driving. Institute for Human Psychopharmacology, University of Maastricht.

Robbe HWJ, O'Hanlon JF (1993). Marijuana and Actual Driving Performance, DOT HS 808 078, National Highway Traffic Safety Administration, US Department of Transportation, Washington D.C.

Smiley AM (1989). Marijuana: On-road and driving simulator studies. Alcohol, Drugs and Driving, 2, 121-134.

Smiley AM, Noy YI, Tostowary KW (1987). The effects of marijuana alone and in combination with alcohol on driving performance. In: PC Noordzij and R Roszbach (Eds.) Alcohol Drugs and Traffic Safety - T86. Excerpta Medica, Amsterdam, 203-206.

Soderstrom CA, Trifillis AL, Shankar BS, Clark WE, Cowley RA (1988). Marijuana and alcohol use among 1023 trauma patients. Archives of Surgery, 123, 733-737.

Stein AC, Allen RW, Cook ML, Karl RL (1983). A Simulator Study of the Combined Effects of Alcohol and Marijuana on Driving Behavior. DOT HS 806 405, National Highway Traffic Safety Administration. US Department of Transportation, Washington D.C. 
Marijuana / Alcohol Driving Study

Terhune KW (1982). The Role of Alcohol, Marijuana and Other Drugs in the Accidents of Injured Drivers. Calspan Field Services Inc., Buffalo, New York. Tech. Rep. under Contract No. DOT-HS-5-01179.

Terhune KW, Ippolito CA, Hendriks DL, Michalovic JG (1992). The Incidence and Role of Drugs in Fatally Injured Drivers. National Highway Traffic Safety Administration, US Department of Transportation, Washington D.C. Final Rep under Contract No. DTNH 22-88-C-07069

Van Laar MW, Volkerts ER, Willigenberg AAP (1992). Therapeutic effects and effects on actual driving performance of chronically administered buspirone and diazepam in anxious outpatients. Journal of Clinical Psychopharmacology, 12, 86-95.

Vuurman EFPM, Muntjewerff ND, Uiterwijk MMC, van Veggel LMA, Crevoisier C, Haglund L, Kinsig M, O'Hanlon JF (1996). Effects of mefloquine alone and with alcohol on psychomotor and driving performance. European Journal of Clinical Pharmacology, 50, 475-482.

Williams AF, Peat MA, Crouch DJ, Wells JK, Finkle BS (1985). Drugs in fatally injured young drivers. Public Health Reports, 100, 19-25.

Yesavage JE, Leirer VO, Denari M, Hollister LE (1985). Carry-over effects of marijuana intoxication on aircraft pilot performance: a preliminary report. American Journal of Psychiatry, 142, 1325-1329.

Young AM, Goudie AJ (1994). Adaptive processes regulating tolerance to behavioral effects of drugs. In: FE Bloom, DJ Kupfer (Eds.) Psychopharmacology: The Fourth Generation of Progress. Raven Press, New York. 
DOT HS 808939

July 1999

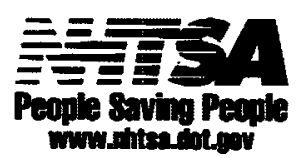

